\title{
Participation of Eag1 in tumor relevant pathways.
}
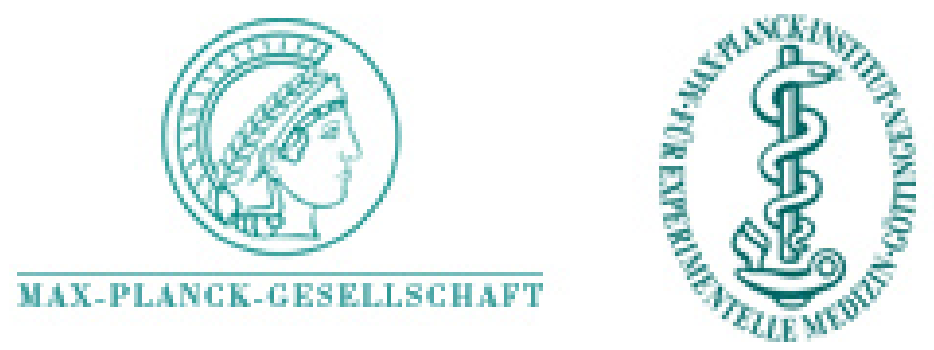

Bryan Downie

Max Planck Institute of Experimental Medicine

Georg-August Universität, Göttingen

A thesis submitted for the degree of

PhilosophiceDoctor (PhD), DPhil,..

September 2009 
1. Reviewer: Name

2. Reviewer:

Day of the defense:

Signature from head of $\mathrm{PhD}$ committee: 


\begin{abstract}
Ether--go-go-1 (Eag1) is a CNS-localized voltage-gated potassium channel that is found ectopically expressed in a majority of extra-cranial solid tumors. While circumstantial evidence linking Eag1 to tumor biology has been well established, the mechanisms by which the channel contributes to tumor progression has until recently remained elusive.

In this study, we have used in vivo and in vitro techniques to identify Eag1 interactions with HIF-1 regulatory system as a candidate mechanism. Eag1 functionally and physically interacts with HIF prolyl hydoxylases (PHD) and immunoprecipitates with ubiquitin and pVHL. Eag1 ubiquitin immunoprecipitation is PHD dependent, and Eag1 undergoes proteasomal degradation. Eag1 expression stabilizes HIF and promotes VEGF secretion and angiogenesis in vivo.

Our data suggest that Eag1 interferes with the cellular mechanism for maintaining oxygen homeostasis, increasing HIF-1 activity, and thereby VEGF secretion and tumor vascularization.
\end{abstract}


To ... 


\title{
Acknowledgements
}

\author{
Walter Sthmer Luis Pardo Araceli Sanchez Fernanda Mello De Queiroz \\ Jens Koeditz and Dorthe Katschinski Marieke Wottawa Victor Diaz David \\ Gomez-Varela Ye Chen Ute Rust \\ Creator of the Phd template Bill Marcia, mom and Dad, Keir and Reid \\ Christine Gehrig \\ I would also like to acknowledge the thousands of individuals who have \\ coded for the LaTeX project for free. It is due to their efforts that we can \\ generate professionally typeset PDFs now.
}




\section{Contents}

List of Figures vii

1 Introduction 1

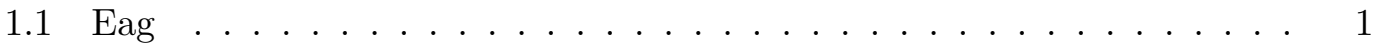

1.1 .1 Eag1 structure . . . . . . . . . . . . . . 1

1.1.2 Eag1 binding partners and modulators . . . . . . . . . 2

1.1.3 Eag1 and cell proliferation . . . . . . . . . . . 3

1.1.4 Eag1 and cancer . . . . . . . . . . . . . . . 3

1.2 Hypoxia and Cancer . . . . . . . . . . . . . . 4

1.2 .1 HIF Expression . . . . . . . . . . . . . . . प

1.2 .2 HIF targets . . . . . . . . . . . . . 5

1.2 .3 PHD and HIF $\ldots \ldots \ldots \ldots \ldots$

1.2 .4 pVHL and HIF . . . . . . . . . . . . . . 7

1.2.5 Tumors and hypoxia .............. 7

1.2 .6 Ubiquitin . . . . . . . . . . . . . . . . . 7

1.2 .7 Eag1 and VHL . . . . . . . . . . . . 8

2 Aims of the project 9

$2.1 \quad$ Project Scope . . . . . . . . . . . . . . . . . . . . . . . . 9 9

2.2 Goals . . . . . . . . . . . . . . . . . . 9

3 Results 11

3.1 Physical interaction with the HIF pathway . . . . . . . . . . 11

3.1 .1 Eag1 and hypoxia ............... 11

3.1 .2 Eag1 and PHD . . . . . . . . . . . . . 14

3.1 .3 Eag1 and VHL . . . . . . . . . . . . . . . 17 
3.1.4 Eag1 and ubiquitylation . . . . . . . . . . . . 19

3.2 Functional interaction with the HIF pathway . . . . . . . . . . 20

3.2.1 Effect of PHD and VHL knockdown on Eag1 . . . . . . . . . 20

3.2.2 Effect of PHD and VHL transfection on Eag1 . . . . . . . . 22

3.2.3 In vitro ubiquitylation assay of Eag1 c-terminus . . . . . . . . 23

3.3 Possible Eag1 degradation pathways . . . . . . . . . . . . . 24 24

3.3.1 Eag1 and the proteosome . . . . . . . . . . . 24

3.3 .2 Eag1 and the lysosome . . . . . . . . . . . . 25

3.4 Eag1 induction of HIF and it's consequences . . . . . . . . . . 26

3.4.1 Eag1 expression stabilizes HIF-1 . . . . . . . . . . . . . 26

3.4 .2 Eag1 and VEGF . . . . . . . . . . . . . . . . . 30

3.4.3 Tissue consequences of Eag1 expression . . . . . . . . . . 32

4 Other experiments 35

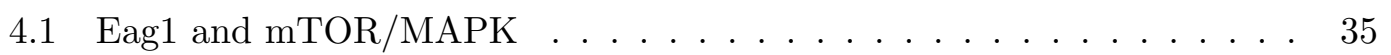

4.1 .1 Eag1, HIF, and mTOR . . . . . . . . . . 35

4.1.2 Eag1 expression and MAPK . . . . . . . . . . . . 36

4.1 .3 Conclusions . . . . . . . . . . . . . . . . 37

4.2 siRNA knockdown of Eag1 current density . . . . . . . . . . . 39

4.3 Chemical modification of HERG blockers to reduce channel affinity . . . 39

4.3 .1 NMA block of HERG . . . . . . . . . . . . . . 40

4.3 .2 Conclusion . . . . . . . . . . . . . . . . . . . . 41

5 Discussion 43

5.1 Eag1 physically and functionally interacts with prolyl hydroxylases . . . 43

5.2 Eag1 physically and functionally interacts with VHL . . . . . . . . 4 45

5.3 Eag1 is ubiquitylated and is proteasomally degraded. . . . . . . . . . 46 46

5.4 Eag1 stabilizes HIF-1 . . . . . . . . . . . . . . . . . . . . 47

5.5 Eag1 expression induces VEGF secretion and neo-angiogenesis . . . . 47

5.6 Eag1 may promote tumorigenesis via competitive inhibition . . . . . . 47

5.7 Eag1 and the brain . . . . . . . . . . . . . . . . . 48

5.8 Eag1 likely promotes tumorigenesis via interaction with intracellular do-

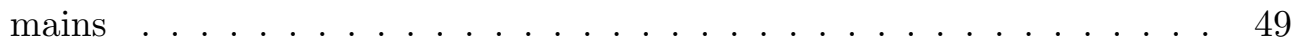


6 Materials \& methods 51

6.1 Cell Culture . . . . . . . . . . . . . . . . . . . . . 51

6.2 Flow Cytometry . . . . . . . . . . . . . . . . 51

6.3 Electrophysiology . . . . . . . . . . . . . . . . 52

6.4 Transient transfection . . . . . . . . . . . . . . . 552

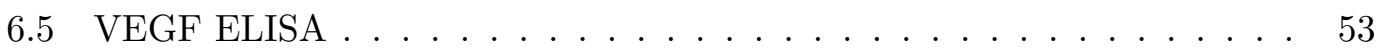

6.6 Immunoprecipitation and western blot . . . . . . . . . . . . 55

6.7 In vitro transcription-translation (IVTT) and ubiquitylation assay . . 54

6.8 Radioactive labelling . . . . . . . . . . . . . . . . . . 555

6.9 Mouse model . . . . . . . . . . . . . . . . . . . . 55

6.10 Luciferase assay . . . . . . . . . . . . . . . . . 555

6.11 Inmunohistochemistry . . . . . . . . . . . . 55

References 
CONTENTS 


\section{List of Figures}

1.1 Structure of $\operatorname{Eag} 1$ protein $\ldots \ldots \ldots \ldots$ 2 . . . . . . . .

1.2 A selection of HIF target genes . . . . . . . . . . . . . . 6

1.3 Regulation of HIF-1 expression. . . . . . . . . . . . . . 6 6

3.1 Eag current density under hypoxia . . . . . . . . . . . . . 12

3.4 Eag1 expression does not induce redox changes . . . . . . . . . . 12

3.2 Eag1 current reduction due to cycloheximide . . . . . . . . . . . 13

3.3 Eag1 current density affected by mimickers of hypoxia . . . . . . . . . 13

3.5 Yeast 2-Hybrid screen between Eag1 and PHD2 . . . . . . . . . . . . 14

3.6 Yeast 2-Hybrid screen between Eag1 and PHD3 . . . . . . . . . . 15

3.7 Yeast 2-Hybrid screen between Eag1 and PHD1 . . . . . . . . . . 15

3.8 HEK293 Clone A expression of PHDs . . . . . . . . . . . . . . . 16

3.9 Immunoprecipitation of Eag1 with PHD2 . . . . . . . . . . . . . . 16

3.10 GST pulldown of VHL and Eag1 N-terminal . . . . . . . . . . . . . 17

3.11 GST pulldown of VHL and Eag1 C-terminal . . . . . . . . . . . 18

3.12 Immunoprecipitation of Eag1 with VHL in HEK293 and SHSY-5Y . . . 18

3.13 Immunoprecipitation of Eag1 with Ub in HEK293 . . . . . . . . . . . 19

3.14 Eag1 interaction with PHD . . . . . . . . . . . . . 20

3.15 Eag1-Ubiquitin immunoprecipitation is affected by PHD and VHL knockdown . . . . . . . . . . . . . . . . . . . . 21

3.16 Eag1 interaction with PHD and VHL . . . . . . . . . . . 22

3.17 in vitro ubiqutylation of Eag1 c-terminus. . . . . . . . . . . . . . . 223

$3.18 \mathrm{~S}^{35}$ labelled Eag1 degradation . . . . . . . . . . . . . . . . 24

3.19 Eag1 interaction with the proteasome . . . . . . . . . . . 25

3.20 Eag1 interaction with the lysosome . . . . . . . . . . . . 26 


\section{LIST OF FIGURES}

3.21 HIF-1 changes in Clone A using flow cytometry. . . . . . . . . . . 27

3.22 HIF-1 changes in three monoclonal Eag1 cell lines. . . . . . . . . . . 28

3.23 HRE response in Eag1 expressing cells. . . . . . . . . . . . . 28 28

3.24 Changes in HRE induction in Eag1-expressing cells. . . . . . . . . 2. 29

3.25 HIF expression under mild hypoixa. . . . . . . . . . . . . . 30

3.26 Eag1 knockdown influence on HIF-1 expression. . . . . . . . . . . . . 31

3.27 Effect of non-targetted siRNA on HIF response. . . . . . . . . . . . . 31

3.28 VEGF secretion from Eag1 cells . . . . . . . . . . . . . . 32

3.29 Eag1-mediated VEGF secretion in non-human cells. . . . . . . . . . 33

3.30 Vascular staining of Eag1 and control tumors . . . . . . . . . . 33

4.1 Eag1-induced alteration in HIF expression under rapamycin. . . . . . 36

4.2 Eag1-induced alteration in VEGF secretion under rapamycin. . . . . . 37

4.3 HEK PT activation of MAPK $/ \mathrm{mTOR} \ldots \ldots \ldots \ldots$

4.4 Eag1 activation of MAPK $/ \mathrm{mTOR} \ldots \ldots \ldots \ldots$

4.5 Eag1knockdown by siRNA . . . . . . . . . . . . . . 39

4.6 HERG current in response to N-Methyl Astemizole . . . . . . . . . . . . 40 


\section{1}

\section{Introduction}

\section{$1.1 \quad$ Eag}

The eag ion channel family is an important class of potassium-permeant ion channels that includes members of the eag, erg, and elk sub-families (1). As the founding member of this family (2, 3), Eag1 has been studied for its role in both excitable and non-excitable cells. Eag1 expression is largely restricted to the central nervous system, where widespread mRNA $(\underline{4}, 5$ ) and protein $(\underline{6})$ expression is found.

\subsubsection{Eag1 structure}

As a potassium ion channel, Eag1 shares certain homologies with other potassium channels. It is composed of a tetramer with each subunit consisting of an amino terminus, 6 transmembrane segments (S1-S6, including the voltage sensor S4), a pore region, and carboxy terminus (Figure 1.1). Eag1 is distinct in both the size of the N-terminus ( 200 amino acids) and the C-terminus ( 500 amino acids) as well as the distinct "Cole-Moore shift" (7) it exhibits. Within the C-terminus is found a tetrameric coiled coil domain (TCC) (8), which induces very strong intra-subunit binding and is likely a key factor in channel assembly.

Eag1 has many candidate interaction domains as determined by homology, including PKA, PKC, CaMK2, cyclic nucleotide binding domain (cNBD), a nuclear localization signal (NLS), and a calmodulin binding domain ( $\mathrm{CaM}$ ). The C-terminus in particular has extensive putative binding domains, and several binding partners have been identified to modulate Eag1 activity by binding to the C-terminus. 


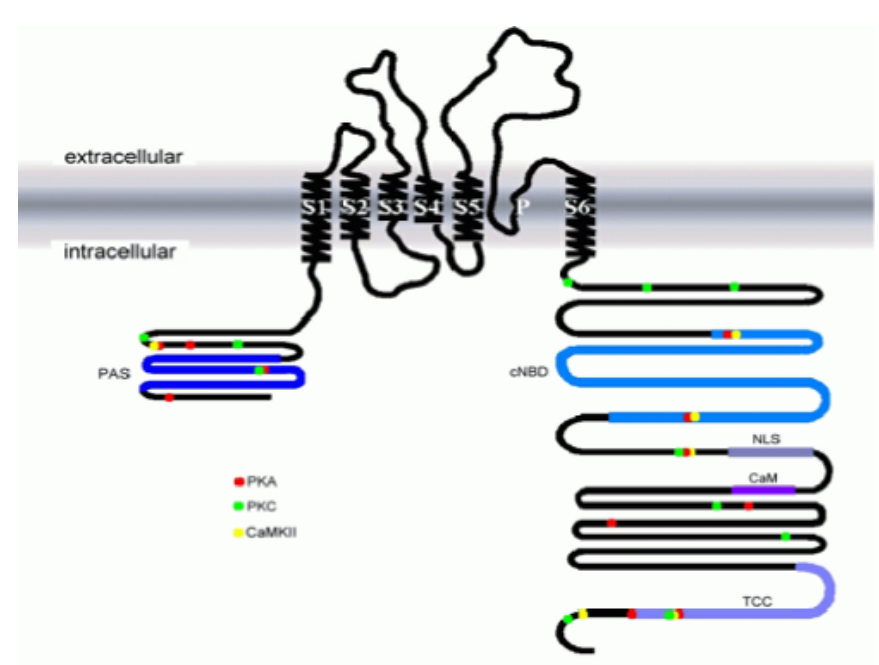

Figure 1.1: Structure of Eag1 protein - Eag1 has an extensive pore region located between S5 and S6 transmembrane segments and a very large N- and C- terminus. PAS: Per-Arnt-Sim domain, cNBD: cyclic nucleotide binding domain, NLS: Nuclear localization signal, CaM: Calmodulin binding domain, TCC: tetrameric coiled coil domain, PKA: protein kinase A, PKC: protein kinase C, CaMKII: calmodulin-dependent kinase 2 domain.

\subsubsection{Eag1 binding partners and modulators}

One of the most notable and unique identifiers of Eag1 is the pronounced "Cole-Moore shift" (7) it exhibits, in which the kinetics of activation are dependent on the pre-pulse potential. In the case of Eag1, the Cole-Moore shift is extremely pronounced, causing an activation delay of $100 \mathrm{~s}$ of milliseconds after a $20 \mathrm{mV}$ change of the conditioning pulse (9). This shift is dependent not only on pre-pulse potential, but also on extracellular $\mathrm{Mg}^{2+}(10) \cdot \mathrm{Mg}^{2+}$ binds to the extracellular hydrophilic loop between S2 and S3 and slows channel gating (11).

Eag1 current is also blocked by intracellular $\mathrm{Ca}^{2+}(12)$ which occurs through a calmodulin dependent mechanism. Activated calmodulin binds to both the amino- and carboxy-termini (13, 14) and inhibits Eag1 current, perhaps by sterically preventing channel opening. It was also observed that calmodulin-dependent kinase 2 (CamK2) binds and phosphorylates Eag1 in Drosophilia through an unrelated pathway (15), providing an alternate candidate mechanism for $\mathrm{Ca}^{2+}$ block of Eag1. To complicate matters further, Eag1 has been shown to interact with Camguk/CASK adapter protein (16), which also interacts with CamK2. 
Finally, epsin co-expression with Eag1 in HEK293 cells shows a slowing of channel activation in physiologically relevant voltage ranges (17). Epsin has been implicated in endocytosis and is expressed in synaptic terminals, where Eag1 is also found. Eag1 is also affected by cytoskeletal interactions, as actin filament disruption increases current density in transfected $\mathrm{CHO}$ cells while microtubule disruption reduces current density (18). Moreover, Eag1 is expressed during myoblast fusion (19), a process that requires extensive cytoskeletal remodeling.

\subsubsection{Eag1 and cell proliferation}

One of the most curious and compelling consequences of Eag1 expression arose after the identification of its role in the cell cycle and cellular proliferation. Eag1 current in Xenopus oocytes was found reduced during the maturation phase, a phenomenon that could be reproduced by co-injection of mitosis-promoting factor (20).

Eag1 expression was also discovered to induce a transformed phenotype in transfected cells, characterized by a loss of dependence on growth factors and in a loss of contact inhibition (21). Moreover, inhibition of Eag1 expression using both antisense oligonucleotides and siRNA (22) has been found to reduce cellular proliferation. Inhibiting Eag1 using the open channel blockers astemizole or imipramine also reduces cell proliferation in vitro (23; 24).

Finally, blocking Eag1 permeation by treatment with a pore-directed antibody was found to inhibit cellular proliferation in both heterologous and natively expressing cells (25).

\subsubsection{Eag1 and cancer}

Cancer causes approximately $13 \%$ of all deaths worldwide (26) and $25 \%$ of deaths in industrialized countries. As a disease that primarily afflicts older people, this fraction of deaths caused is expected to increase as lifespan continues to increase. By 2020, the number of new cancer cases is expected to grow by $50 \%$ (27).

After the report of a link between cell proliferation and Eag1 expression, researchers began to investigate links between cancer and Eag1 expression. Eag1 ectopic expression was observed in many cancer cell lines, including SHSY-5Y (28), IGR1 and IPC298 (29), EFM-19, MCF-7, and HeLa (21). Moreover, Eag1 protein has been detected in 


\section{INTRODUCTION}

a wide range of human cancers, including soft tissue sarcomas (30) and cervical cancer (31). Furthermore, Eag1 was found in over $70 \%$ of all cancerous tissues screened (32), while the corresponding healthy tissue was consistently free of Eag1 expression, indicating an important link between Eag1 expression and cancer. Perhaps most intriguing, more aggressive soft tissue sarcomas were shown to express more Eag1 than less aggressive soft tissue sarcomas (30). This relationship between Eag1 expression and patient outcome suggests a direct link between Eag1 and poor prognosis.

Eag1-expressing tumors in SCID mice are also larger and more aggressive than tumors that do not express Eag1 (21). We recently reported that Eag1-expressing tumors are reduced in size by treatment with astemizole, a reduction similar to that observed with cyclophosphamide treatment, a well established cytotoxic agent (33).

Interestingly Eag2, a 70\% identical homolog of Eag1 (4), shows no relationship to either cell proliferation or cancer. Eag2 shares many features with Eag1, including both the $\mathrm{Mg}^{2+}$, voltage-dependent Cole-Moore shift and a similar I-V relationship (34) (though it opens at more negative voltages (35)). Moreover, it's expression is also largely restricted to the CNS (5) and is a candidate for the formation of heterotetrameric Eag proteins. The absence of tumorigenic potential in Eag2 suggests that the contribution of Eag1 to oncogenesis is only partly dependent on its canonical role as an ion conductor, and may be more dependent on the large intracellular domains where the least homology between Eag1 and Eag2 lie.

\subsection{Hypoxia and Cancer}

\subsubsection{HIF Expression}

Hypoxia exposure immediately leads to expression of the transcription factor Hypoxia Inducible Factor-1 (HIF-1). The HIF transcription factor family is composed of 3 isoforms, HIF-1, HIF-2, and HIF-3, of which HIF-1 is the best studied and described. HIF-1 is composed of a constituitively expressed $\beta$ subunit and an $\alpha$ subunit which is tightly regulated by prolyl hydroxylases (PHDs) and von-Hippel Lindau protein (pVHL). Under hypoxic conditions, HIF-1 $\alpha$ is expressed and dimerizes with HIF-1 $\beta$, translocates to the nucleus, and promotes transcription of hypoxia-inducible genes. HIF-1 induction by hypoxia occurs near instantaneously, with a peak HIF-1 expression approximately 4 hours after onset (depending on the cell line) (36). HIF-1 starts to 
stabilize at approximately 5-6\% atmospheric $\mathrm{O}^{2}$, with half maximal activation occurring near $2 \% \mathrm{O}^{2}$ (37). HIF can be chemically induced by desferrioxamine (DFO) (38), $\mathrm{Co}^{2}+$, and dimethyloxaloylglycine (DMOG).

\subsubsection{HIF targets}

HIF-1 was originally identified as a promoter of erythopoetin (EPO) expression (39) by binding to the "hypoxia response element" (HRE) of EPO under hypoxia (40). Since then, HIF-1 has been shown to target a wide variety of hypoxia related genes, including those involved in cell proliferation, metabolism, survival, inflammation, erythropoesis and vascularization (Figure 1.2). One of the most influential targets of HIF-1 is vascular endothelial growth factor (VEGF), a growth factor critical to the formation of new blood vessels.

\subsubsection{PHD and HIF}

The HIF prolyl hydroxylases (PHDs) are a conserved family of 2-oxoglutarate and irondependent dioxygenases that are the key oxygen sensors of the HIF regulation system. PHD function is dependent on ascorbate as a co-factor and is inhibited by DFO, $\mathrm{Co}^{2}+$ and DMOG. PHD2 is the primary cellular oxygen sensor for HIF-1 under normal oxygen conditions (41) and recognizes a LXXLAP motif (42) at P402 and P564 of HIF- $1 \alpha$ (aka the oxygen-dependent degradation domain; ODD)(43). PHD hydroxylates HIF$1 \alpha$ prolines (44; 45) using atmospheric oxygen, tagging it for identification by pVHL (46) (Figure 1.3). Prolonged hypoxia drives expression of PHD3 via HIF-1, generating an inhibitory feedback machanism (47) as PHD3 hydroxylates HIF-1. Moreover, the $\mathrm{O}_{2} \mathrm{~K}_{m}$ of PHD3 is substantially lower than that of PHD2 (48), allowing it to function in lower oxygen concentrations.

PHD interactions are not restricted to HIF regulation alone, however. PHD3 interacts with and stabilizes the activating transcription factor-4 (ATF-4), indicating a dual role for the PHD3 protein (51). Additionally, PHD2 has recently been shown to interact with and be stabilized by FKB38 (52, 53). 


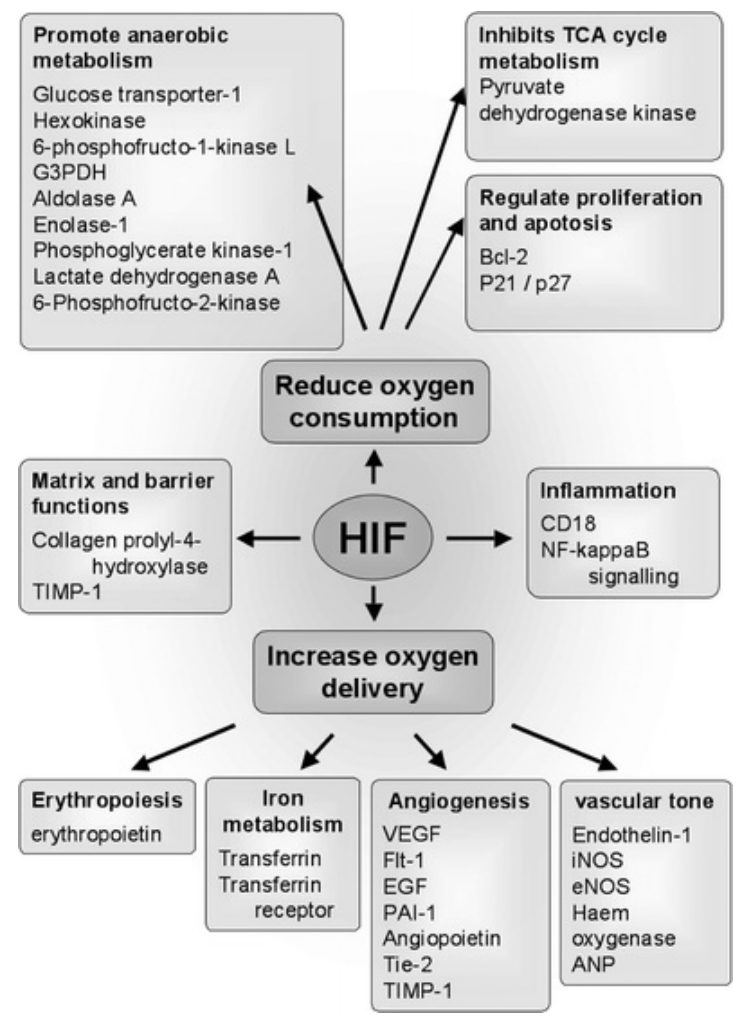

Figure 1.2: A selection of HIF target genes - taken from (49)

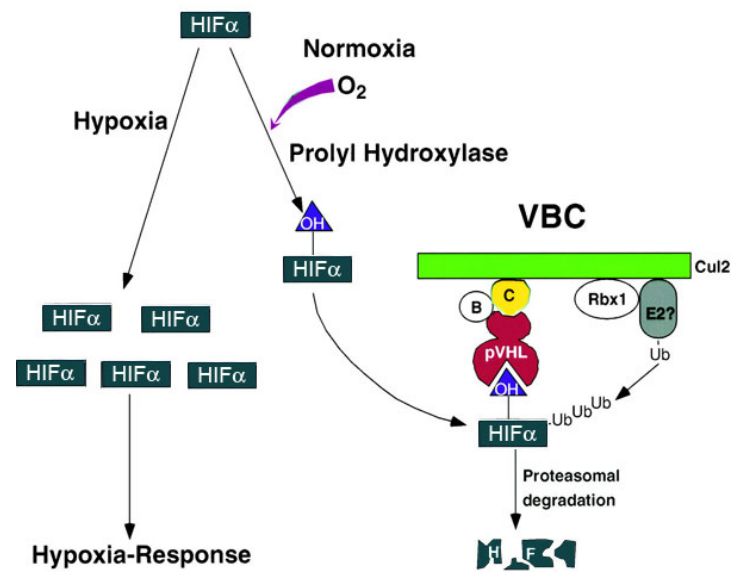

Figure 1.3: Regulation of HIF-1 expression. - HIF-1 $\alpha$ is recognized under normoxia and hydroxylated by prolyl hydroxylases. Hydroxylated HIF- $1 \alpha$ is recognized by pVHL and ubiquitylated, then degraded by the proteasome. Under hypoxic conditions, hydroxylation is inhibited and HIF- $1 \alpha$ escapes degradation and promotes transcription of hypoxia-relevant genes. Taken from (50) 


\subsection{4 pVHL and HIF}

Von-Hippel Lindau disease is a rare autosomal genetic disease characterized by the spontaneous formation of hemangioblastomas in the cerebellum, spinal cord, and retina. First described by Eugen von Hippel in 1904 (54), VHL disease is caused by a mutation in the vhl gene, commonly on or near Y98. These mutants cause the VHL disease by inhibiting the ability of pVHL to recognize HIF. pVHL is a subunit of the E3 ubiquitin ligase VHL complex (55) which includes Elongins B and C, Cul2, and Rbx1. pVHL ubiquitylates hydroxylated HIF, targetting it for the proteasome and proteolysis (56). Y98 is a critical residue for HIF recognition $(57,58)$ and mutation of the residue blocks HIF ubiquitlyation. R167 is an important residue for binding to Elongins B and C and expression of the R167W mutant prevents HIF-1 ubiquitylation by the mutant.

VHL has been proposed to have additional functions as well. pVHL has been proposed to promote inhibitory phosphorylation of the NF- $\kappa$ B agonist Card 9 by direct binding (59), acting outside its putative role as a member of an E3 ligase complex. VHL activity has also been proposed as relevant during neuronal differentiation (60), independent of its role in regulating HIF-1 activity.

\subsubsection{Tumors and hypoxia}

Tumors are hypoxic environments. As they grow, new cells are added to the periphery of the tumor while those in the tumor core become increasingly deprived of oxygen, glucose, and other nutrients. Eventually, this starvation leads to hypoxia-induced apoptosis and necrosis (61). In order to increase in volume beyond a few $\mathrm{mm}^{3}$, tumors must form new blood vessels to oxygenate their cells (For review, see (62)). This cellular switch to turn on angiogenesis is highly dependent on oxygen concentration and occurs via a HIF-1 dependent signal transduction process involving VEGF.

\subsubsection{Ubiquitin}

Ubiquitin is a small, $8 \mathrm{kDa}$ protein that is conjugated onto lysine residues of other proteins. First characterized as a signal for protein degradation, a broad spectrum of alternate conjugations has lead to a greater understanding of ubiquitin more generally as a trafficking signal. Increasingly, other ubiquitin-like proteins (UBL) such as SUMO (63) and Nedd8 $(64 ; 65)$ are being identified as alternative signaling mechanisms for 


\section{INTRODUCTION}

trafficking and protein function. Ubiquitin and other UBL signalling has also been demonstrated to be important for ion channel trafficking and expression (for review, see $(66$; 67$)$ ).

\subsubsection{Eag1 and VHL}

In 2002, a team of researchers researching the role of VHL on differentiation reported that VHL expression caused differentiation of SHSY-5Y neuroblastoma cells into neuron-like cells. In order to further demonstrate differentiation, they measured Eag1 current density and noted a reduction of Eag1 in stably-transfected VHL cells. Moreover, an increase in Eag1 current was observed in stable clones that showed inhibition of VHL expression (68). These data were not analyzed further, but rather presented simply as demonstration of various stages of VHL-induced differentiation.

We interpreted this report as evidence of a possible cross-talk between Eag1 and the HIF regulatory pathway. We also had previously observed a LXXLAP motif just outside the PAS domain in the N-terminus of Eag1. We consequently began investigating whether Eag1 physically and functionally interacts with PHD, VHL, or the proteasome, and what the ramifications of any such interaction would be. 


\section{2}

\section{Aims of the project}

\subsection{Project Scope}

This project had two concurrent primary objectives. First, to identify whether the Eag1 ion channel is functionally modified by components of the HIF-1 cellular degradation system, and the results of any such modifications on Eag1 activity. Second, to determine whether ectopic expression of Eag1 altered the function of the HIF system such that HIF activity and it's downstream effects were altered.

\subsection{Goals}

1. To determine whether Eag1 is directly modified by any member of the PHD family

2. To determine whether VHL functions as an E3 ubiquitin ligase for Eag1.

3. To determine whether any of these candidate interactions affects proteasomal degradation of Eag1.

4. To determine whether Eag1 expression alters expression of HIF and VEGF secretion. 
2. AIMS OF THE PROJECT 


\section{3}

\section{Results}

\subsection{Physical interaction with the HIF pathway}

\subsubsection{Eag1 and hypoxia}

Because of the reported link between VHL expression and Eag1 current density as well as the LXXLAP motif in Eag1 (see 1.2.7), I first studied the effects of chronic hypoxia on steady-state Eag1 expression levels. Both SHSY-5Y (a natively Eag1 expressing neuroblastoma cell line) and stably transfected HEK293 (Clone A) cells were exposed to either $1 \% \mathrm{pO}_{2}$ (hypoxia) or $21 \%$ (atmospheric) $\mathrm{pO}_{2}$ (normoxia) for up to $24 \mathrm{~h}$. Cells were then recorded from using whole-cell patch clamp and current amplitude normalized to cell surface as determined electronically by the patch clamp amplifier. Resulting current density $(\mathrm{pA} / \mathrm{pF})$ from independent cells were processed (see 6.3, aggregated, and statistically compared. No significant differences were detected in current density in either cell line (Figure 3.1).

However, prolonged hypoxia induces a profound alteration in many cellular properties, including cell metabolism and protein synthesis. To limit the impact of any of these effects, I measured the effect of hypoxia on hEag1 current density after inhibition of de novo protein synthesis by cycloheximide. Using the method described above, cells were treated with cycloheximide alone $(10 \mu \mathrm{g} / \mathrm{mL})$ or in conjunction with the prolyl hydroxylase inhibitors $1 \% \mathrm{O}_{2}$ (hypoxia), $\mathrm{CoCl}_{2}(400 \mu \mathrm{M})$ or DMOG $(1 \mathrm{mM})$. The prolyl hydroxylase co-factor ascorbate $(2 \mathrm{mM})$ was used to observe the effects of enhancing prolyl hydroxylase activity. Cycloheximide-alone treated cells showed a 50\% decrease 
HEK-EAG1 (no cycloheximide)

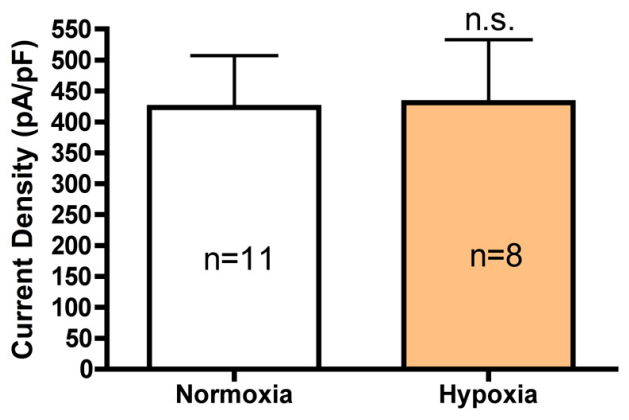

SHSY-5Y (no cycloheximide)

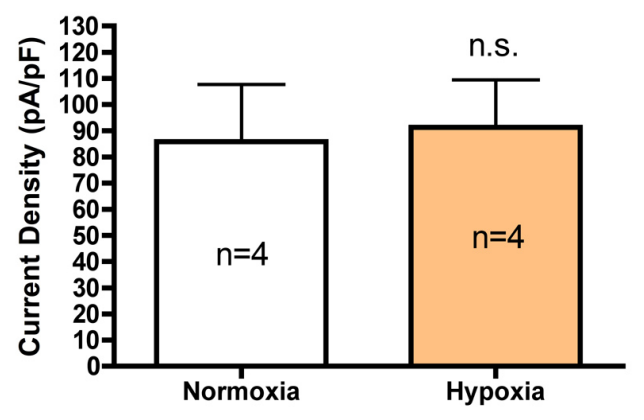

Figure 3.1: Eag current density under hypoxia - Neither SHSY-5Y (left) nor HEK293

Clone A (right) show changes in Eag1 current after $24 \mathrm{hr}$ incubation under hypoxia.

of whole cell current density $(3.2)$ after 8 hours, while 8 hours of hypoxia rescued this effect, indicating a role for $\mathrm{O}_{2}$ in Eag1 surface expression.

Pharmacological mimicking of hypoxia with $\mathrm{CoCl}_{2}$ or DMOG also protected against the decrease in current amplitude induced by cycloheximide. In contrast, pharmacological mimicking of hyperoxia by ascorbate exacerbated the current reduction by a further $50 \%$, to a value approximately $25 \%$ of the normal current density in the absence of cycloheximide (Figure 3.3).

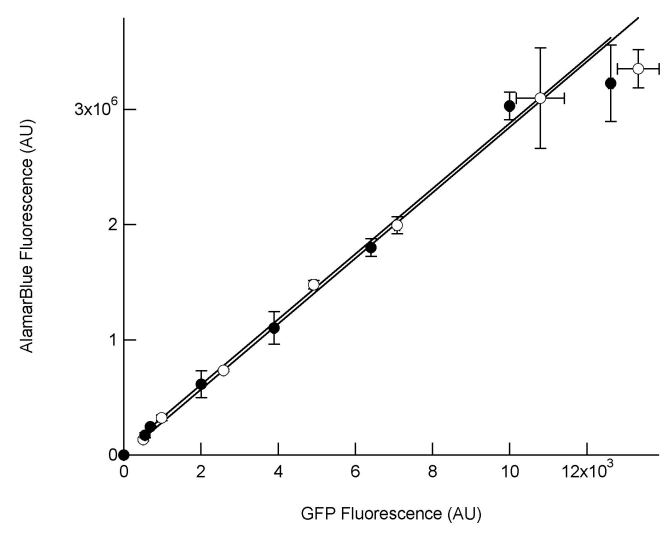

Figure 3.4: Eag1 expression does not induce redox changes - Eag1 expressing cells (white) and HEK-PT cells (black) redox potential was compared. No difference in cellular redox potential was observed.
It is possible that these hypoxiainduced effects are side effects of changes in cellular redox potential due to changes in membrane voltage or interaction with intracellular segments of the channel. To verify that there is no difference in cellular redox potential in Eag1 expressing cells, cells were incubated in the presence of Alamar Blue (Biosource), a dye that is sensitive to cellular oxidation state. The active ingredient in Alamar Blue is resazurin, a non-fluorescent dye that is converted to red-fluorescent resorufin via reduction reactions of metabolically active cells 


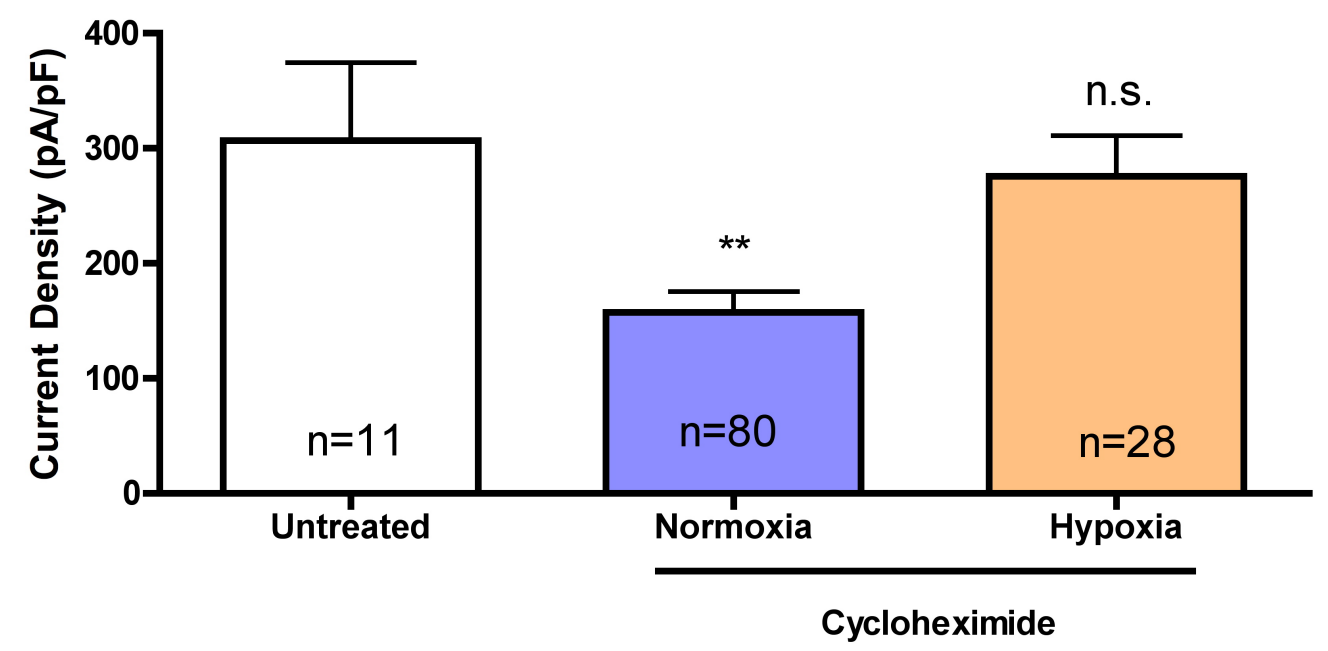

Figure 3.2: Eag1 current reduction due to cycloheximide - Eag1 suffers a reduction of current density upon application of $8 \mathrm{hrs}$ cycloheximide. This current reduction is rescued by incubating the cells in hypoxia.

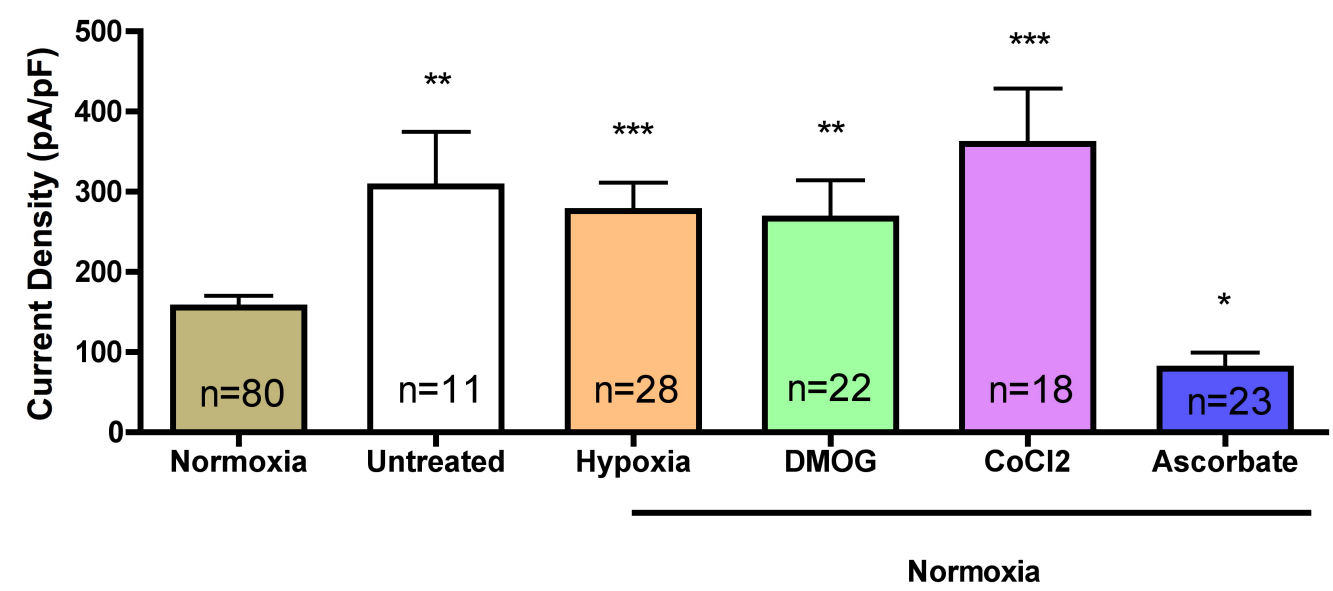

Figure 3.3: Eag1 current density affected by mimickers of hypoxia - $\mathrm{CoCl}_{2}$ and DMOG both rescue current reduction induced by cycloheximide. Current reduction induced by cycloheximide is enhanced by co-culturing with ascorbate. 


\section{RESULTS}

(69). The amount of fluorescence is proportional to the number of living cells. No changes were observed between Clone A and HEK293 cells stably transfected with an empty vector (HEKPT) (Figure 3.4).

Because the effects of hypoxia, DMOG (an inhibitor), and ascorbate (a co-factor) all target the same group of prolyl-4-hydroxylases (PHD), we considered them to be a likely candidate for the direct modulation of hEag1 activity.

\subsubsection{Eag1 and PHD}

In collaboration with Prof. Dr. Katschinski and Dr. Koeditz of the Physiology Department of the University of Göttingen, we first investigated possible in vitro interactions between Eag1 and PHD1, 2 or 3. Because Eag1 is a complex transmembrane protein, purifying the complete protein alone was outside our capabilities. Instead, we chose to investigate only those segments of the channel that would likely interact directly with a water-soluble protein - the intracellular C- and N- termini. For this purpose, we began with a yeast two hybrid screen, performed by Dr. Jens Köditz. Eag1 Nor $\mathrm{C}$ - terminus conjugated to the Gal4 activation domain (AD) was co-expressed with prolyl hydroxylases conjugated to the Gal4 binding domain(BD). HIF- $1 \alpha$-AD was also used as a positive control. Cells were grown on histidine-deficient media in the presence of varying concentrations of 3-Amino-1,2,4-triazole (3AT) in order to titrate the minimum level of HIS3 expression required for growth. No interaction between PHD2 and either the $\mathrm{C}$ - or the N- terminus of Eag1 (Figure 3.5), while the HIF-1 $\alpha$ ODD (oxygen-dependent degradation domain) was observed to interact with PHD2.

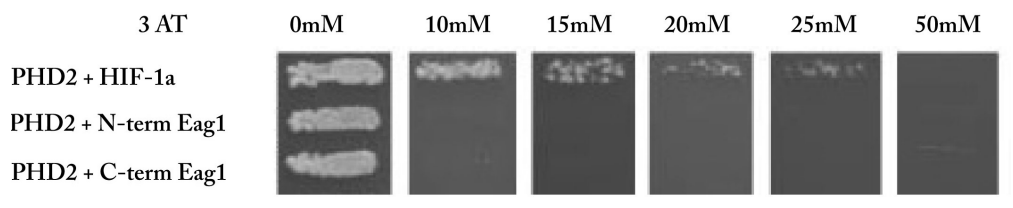

Figure 3.5: Yeast 2-Hybrid screen between Eag1 and PHD2 - Neither N-terminus nor C-terminus of Eag1 interacts with PHD2 (lanes 2, 3). HIF-1 $\alpha$ ODD interacts with PHD2 (lane 1). (Figure provided by Drs. Koeditz and Katchinski)

Both PHD1 and PHD3 interacted with the C-terminus of Eag1, suggesting a strong interaction (Figure 3.6). No such interaction was observed the the N-terminus, suggesting that any interaction could not be mediated by the N-terminus alone. 


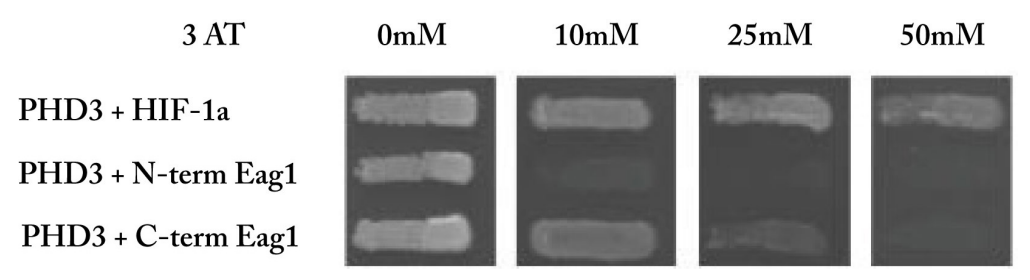

Figure 3.6: Yeast 2-Hybrid screen between Eag1 and PHD3 - PHD3 interacts with the C-terminus of Eag1 (bottom), but not the N-terminus. HIF-1 $\alpha$ strongly interacts with PHD3 as positive control. (Figure provided by Drs. Koeditz and Katchinski)

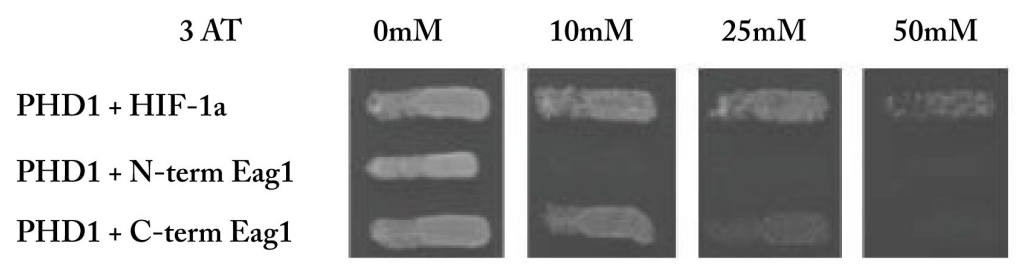

Figure 3.7: Yeast 2-Hybrid screen between Eag1 and PHD1 - PHD1 interacts with the C-terminus of Eag1 (bottom), but not the N-terminus. HIF-1 $\alpha$ strongly interacts with PHD1 as positive control. (Figure provided by Drs. Koeditz and Katchinski)

To further verify the observed interaction with PHDs, we next investigated whether a physical interaction occurred in vivo. Nitrocellulous membranes containing electrophoresed HEK293 Clone A cell extracts were first probed via western blot for expression of each of the prolyl hydroxylases using a PHD antibody sample pack (Novus Biologicals). Clone A cells were found to endogenously express both the constituitively expressed PHD2 and the hypoxia-induced PHD3 (Figure 3.8).

Lysate from Clone A cells was then precipitated using either monoclonal antibodies directed at the pore and C-terminus of Eag1 or an antibody against PHD2. Precipitated protein was then electrophoresed, transferred to nitrocellulous membranes and probed for either PHD2 (former) or Eag1 (latter). PHD2 was found to co-precipitate with Eag1 (Figure 3.9, left), albeit to a lesser extent than Eag1 with itself. Mock-transfected cells showed no reaction, indicating that the antibody used for the detection was specific for Eag1 (data not shown). In contrast, Eag1 was found to co-precipitate with PHD2 (Figure 3.9, right). In this case, some non-specificity in the monoclonal antibodies used to precipitate the extract was observed, as a band was detected where absent in extract precipitated in the absence of antibodies.

Together, these data suggest that the functional regulation of Eag1 surface expres- 


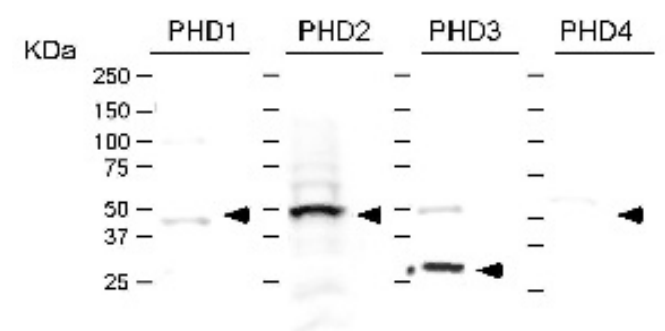

Figure 3.8: HEK293 Clone A expression of PHDs - Clone A extracts show robust expression of both PHD2 and the HIF-induced PHD3. PHDs 1 and 4 do not show strong expression in Eag1-expressing HEK cells. (Figure provided by Dr. Sánchez)

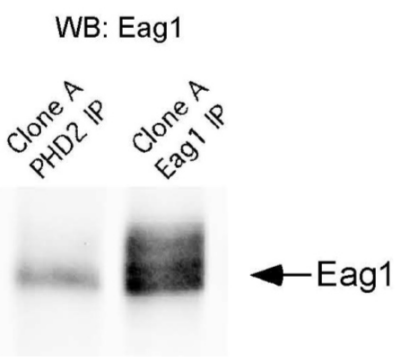

IP: Eag1 WB: PHD2
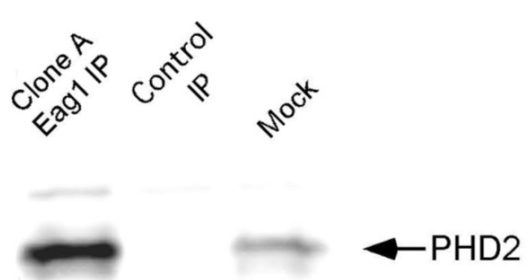

Figure 3.9: Immunoprecipitation of Eag1 with PHD2 - HEK293 Eag1 Clone A cell extracts precipitated with an anti-PHD2 monoclonal antibody can be detected with an anti-Eag1 antibody, while extracts precipitated with an anti-Eag1 antibody show robust detection (left panel). Conversely, extracts precipitated with an anti-Eag1 antibody show a strong PHD2 specific band using an anti-PHD2 antibody (right panel, left). While nonspecific precipitation occurs in extracts prepared from mock-transfected cells (Mock), no precipitation of PHD2 is observed with beads alone. (Figure provided by Dr. Sánchez) 
sion by PHD. This effect may be a direct modification (e.g. hydroxylation) of Eag1 or that of an Eag1 binding partner. However if there is a direct hydroxylation of Eag1 by PHD, it may lead to further interactions between Eag1 and other elements of the HIF regulation system, such as VHL, ubiquitin, and the proteasome.

\subsubsection{Eag1 and VHL}

While other groups have already observed a functional correlation between VHL expression and Eag1 current (68), we wanted to know whether there was a direct interaction between pVHL and Eag1. Using an in vitro GST-pulldown assay, we examined whether there existed a PHD dependent or independent interaction between Eag1 and VHL. GST-tagged Eag1 N- or C- terminus protein was expressed in E. Coli, purified, and immobilized on a glutathione affinity gel. The gel was then treated with a VHL-elonginB-elonginC (VBC) complex and probed for VBC expression.

While either PHD2 or PHD3 were necessary for a VHL interaction with the HIF-2 $\alpha$ ODD, no interaction was observed between VHL and the N-terminus of Eag1 (Figure 3.10. However, the C-terminus of Eag1 was observed to interact with VHL in a PHD independent way, with no increase of VHL pulled down with the addition of PHD2 or PHD3 (Figure 3.11).

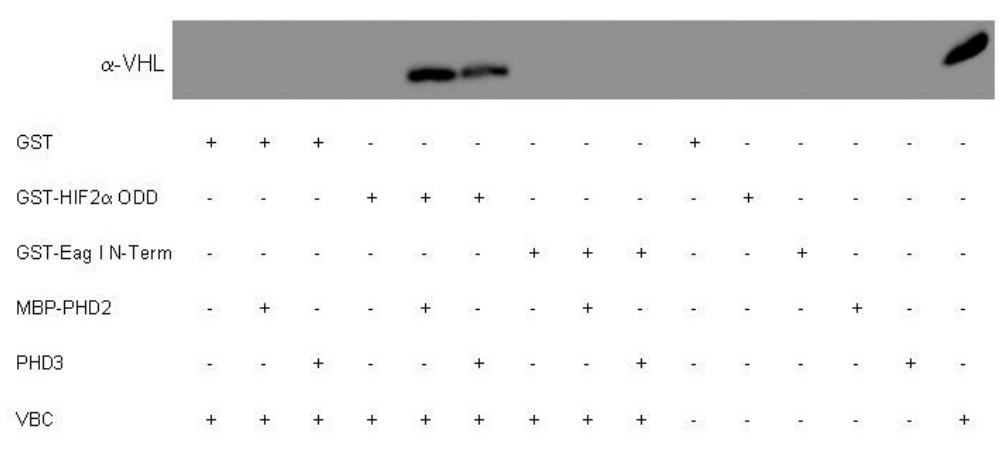

Figure 3.10: GST pulldown of VHL and Eag1 N-terminal - The N-terminal of Eag1 shows no interaction with VHL, either without PHD (column 7), with PHD2 (column 8), or with PHD3 (column 9). HIF-2 $\alpha$ ODD pulls down VHL only in the presence of PHD2 (column 5) or PHD3 (column 6). (Figure provided by Drs. Koeditz and Katchinski)

To verify that this interaction could occur in vivo, we repeated the immunoprecipitation assays above for VHL and Eag1. Clone A cells were chosen for consistency, while SHSY-5Y cells were probed due to the already established functional relationship 


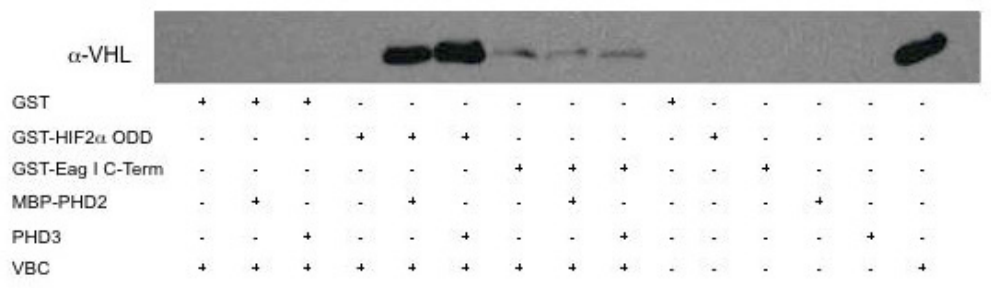

Figure 3.11: GST pulldown of VHL and Eag1 C-terminal - The C-terminal of Eag1 interacts with VHL both with PHD2 and PHD3 (columns 8 and 9) and without PHD (column 7). HIF-2 $\alpha$ ODD pulls down VHL only in the presence of PHD2 (column 5) or PHD3 (column 6). (Figure provided by Drs. Koeditz and Katchinski)

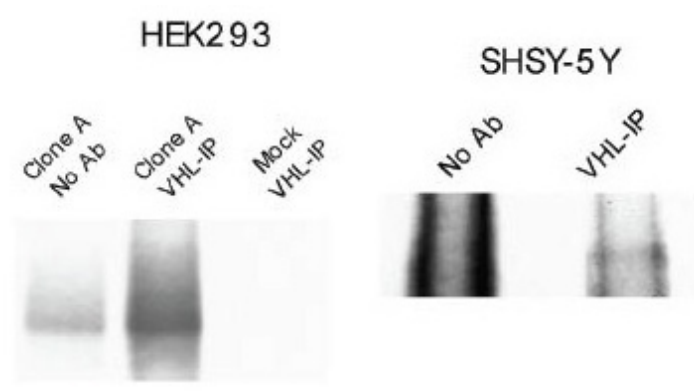

Figure 3.12: Immunoprecipitation of Eag1 with VHL in HEK293 and SHSY-5Y - (left panel) Clone A extracts precipitated with anti-VHL antibody were detected with antibodies against Eag1 (middle lane). No signal was detected in extracts precipitated from mock-transfected cells (right lane) and a faint signal was observed in Clone A extracts precipitated without antibody (left lane). (right panel) SHSY-5Y extracts precipitated with anti-VHL antibody were detected with antibodies against Eag1 (right lane). No signal was observed in SHSY-5Y extracts treated without antibody (left lane).(Figure provided by Dr. Sánchez) 
between natively expressed Eag1 and VHL in these cells. Using an anti-VHL antibody, Clone A extracts showed strong co-precipitation, while SHSY-5Y cells showed faint, but observable, co-precipitation (Figure 3.12). Because the size of VHL is approximately the same as the light chain of the antibody, no Eag1 precipitation and VHL detection was performed. Together, these blots indicate that Eag1 physically interacts with VHL in both heterologous and native systems and supports the interpretation that Eag1 is directly modified by VHL.

\subsubsection{Eag1 and ubiquitylation}

VHL is a well described tumor suppressor that functions as an E3 ubiquitin ligase. It is the only E3 that has been described to recognize the HIF family, and its interaction with Eag1 could lead to ubiquitylation of the ion channel. In order to investigate this, we first wanted to determine whether Eag1 was ubiquitylated in vivo. Cell extracts of Clone A cells treated with MG115 (a potent proteasomal inhibitor, used to enrich ubiquitylated proteins) for 4 hours showed considerable Eag1 specific signal after anti-ubiquitin precipitation (Figure 3.13). No such signal was observed in either mock treated cells or cell extracts precipitated without antibody. This co-immunoprecipitation suggests that Eag1 is ubiquitylated in heterologous systems.

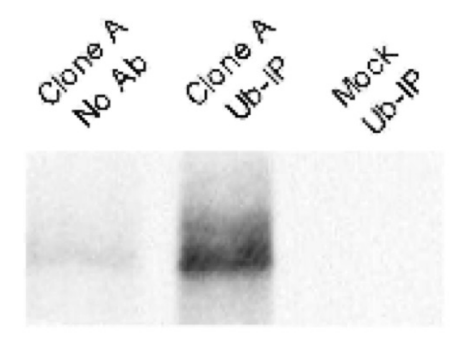

Figure 3.13: Immunoprecipitation of Eag1 with Ub in HEK293 - (Clone A extracts precipitated with anti-Ub antibody were detected with antibodies against Eag1 (middle lane). No signal was detected in extracts precipitated either from mock-transfected cells (right lane) and without antibody (left lane)).(Figure provided by Dr. Sánchez) 


\subsection{Functional interaction with the HIF pathway}

\subsubsection{Effect of PHD and VHL knockdown on Eag1}

Because of the observed interactions between Eag1 and VHL/PHD and because of the co-immunoprecipitation of Eag1 and ubiqutin, I next asked whether Eag1 ubiquitylation was PHD or VHL dependent. Clone A cells were transfected with siRNA targeted against PHD2, PHD3, Eag1, or with a non-coding sequence of siRNA purchased from Ambion (Scrambled). Cells were harvested 2 days after transfection, lysed, and immunoblotted for Eag1 expression. Compared to non-targetted siRNA, knockdown of PHD2 seems to reduce the Eag1-specific high molecular weight signal (Figure 3.14), a finding compatible with PHD-mediated ubiquitylation of Eag1. Important to note, however, is that scrambled siRNA seems to evoke a stabilization of high molecular weight Eag1, most likely due to a siRNA-mediated stress response.

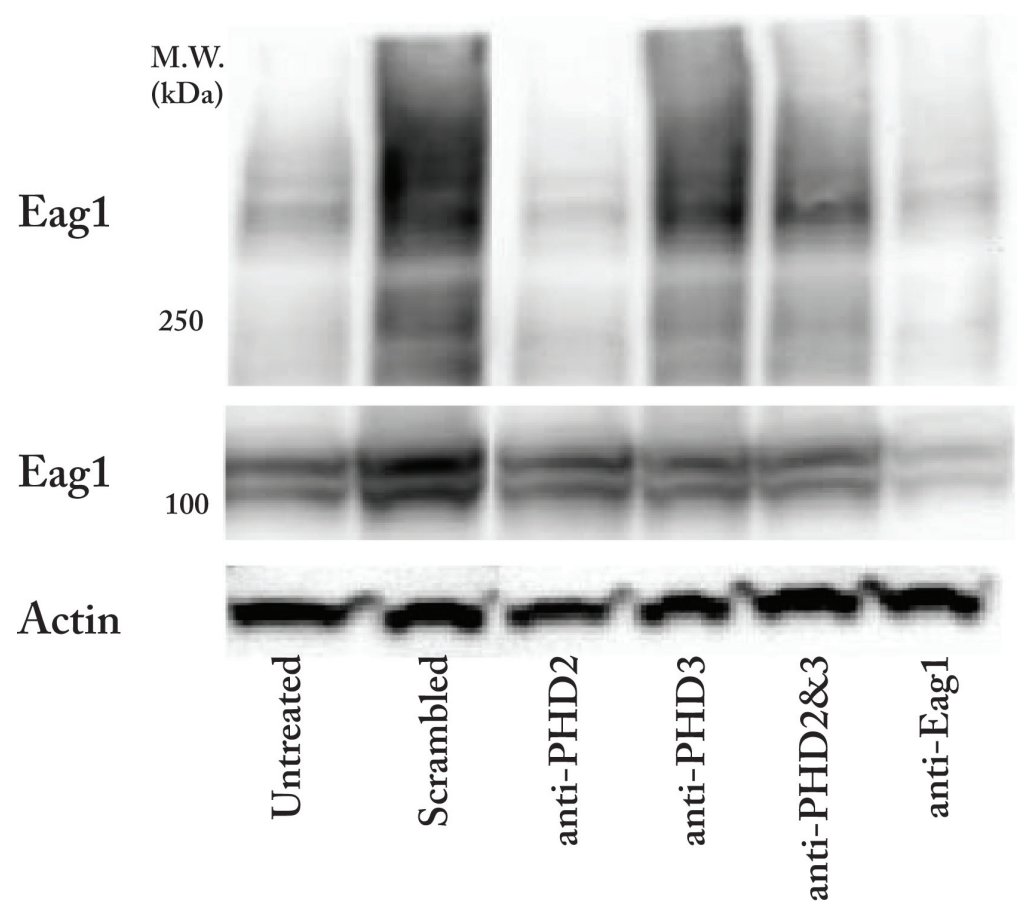

Figure 3.14: Eag1 interaction with PHD - Extracts from siRNA transfected Clone A cells were probed for Eag1 expression. Knockdown of PHD2 decreases the amount of high molecular weight Eag1 (top) as compared to Scrambled, while PHD3 knockdown has a lesser role. No effect of anti-PHD siRNA on the normal 100kDa Eag1 double band is observed (middle). Anti-Eag1 siRNA shows an as-expected reduction of Eag1 protein. 
I next investigated whether this effect on high molecular weight Eag1 upon inhibition of PHD was due to ubiquitylation of Eag1. HEK-Eag1 cells were either transfected with siRNA against PHD or VHL or treated with inhibitors of PHD (hypoxia and DMOG). Untransfected cells were treated for 4 hours with $1 \% \mathrm{O}_{2}$ or $1 \mathrm{mM}$ DMOG, and all cells were treated during this incubation with $10 \mu \mathrm{M}$ MG115 to enrich Eag1ubiquitin immunoprecipitation. Scrambled siRNA was used as a negative control for siRNA treatment. Eag1 protein was precipitated and detected as above (Figure 3.15).

While MG115 treatment alone enriches Eag1-Ub immunoprecipitation (and to a lesser extent enriches Eag1 precipitation), both hypoxia and DMOG treatment cause an overall reduction of Eag1-Ub immunoprecipitation. This hypoxia/DMOG reduction occurs both in the presence and absence of MG115 (data not shown). Moreover, treatment with anti-PHD2, anti-PHD3, and anti-VHL siRNA all slightly reduce Eag1ubiquitin immunoprecipitation. It is also noteworthy that MG115 treatment alone does not enrich detection of the $100 \mathrm{kDa}$ Eag1 double band after immunoprecipitation with anti-Eag1 antibodies. These data indicate that Eag1-ubiquitin immunoprecipitation is at least partly dependent on PHD activity, as inhibition of PHD dramatically reduces Eag1-ubiquitin co-immunoprecipitation.

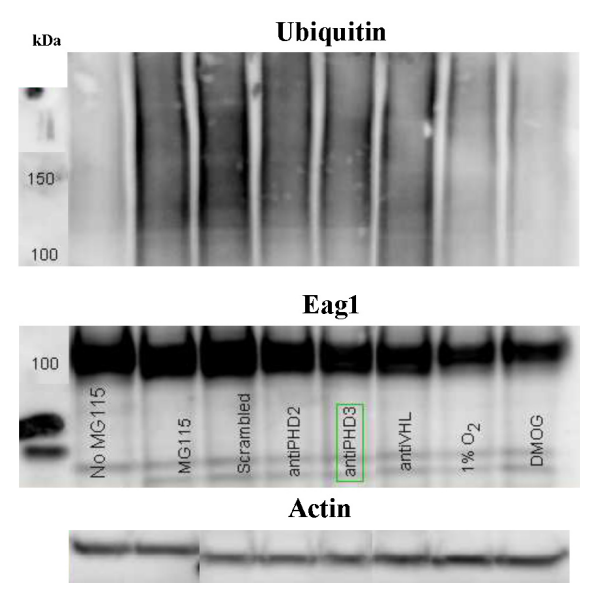

Figure 3.15: Eag1-Ubiquitin immunoprecipitation is affected by PHD and VHL knockdown - HEK cells treated with anti-PHD2, anti-PHD3, or anti-VHL siRNA show reduced Eag1-Ub immunoprecipitation as compared to treatment with non-targetted siRNA (scrambled, top). Treatment with either $1 \% \mathrm{O}_{2}$ or $1 \mu \mathrm{M}$ evokes a stronger reduction of Eag1-ubiquitin immunoprecipitation. All lanes show similar precipitation of Eag1 protein, with the possible exception of hypoxia and DMOG treated cells (middle). Actin probes of $10 \%$ load show equivalent protein load in each lane (bottom) 


\section{RESULTS}

\subsubsection{Effect of PHD and VHL transfection on Eag1}

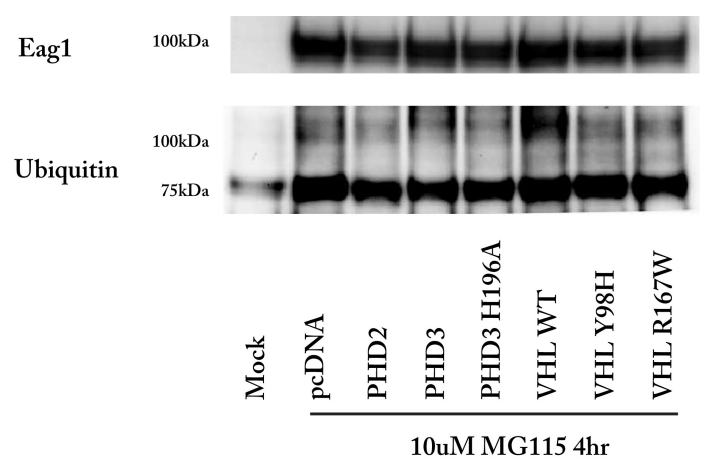

Figure 3.16: Eag1 interaction with PHD and VHL - Cell extracts were precipitated using a combination of monoclonal mouse antibodies against Eag1 and detected with either an anti-ubiquitin antibody (top) or a polyclonal Eag1 antibody (bottom). More Eag1 precipitated with ubiqutin in VHL WT transfected cells as mock transfected cells $(p c D N A)$. Further interpretation is made difficult due to differences in Eag1 precipitation, but PHD2 and PHD3 both appear to affect Eag1 coprecipitation with ubiquitin, while VHL mutants reduce Eag1 co-precipitation with ubiquitin.
Clone A cells were also transfected with PHD, VHL, or the empty vector to determine whether over-expressing PHD or VHL would affect Eag1-ubiquitin coimmunoprecipitation. Clone A cells were transfected with either PHD2 or PHD3, as well as a functional mutant of PHD3 (H196A) which does not hydroxylate HIF. Additionally, VHL wild type and VHL mutants $\mathrm{Y} 98 \mathrm{H}$ (a dominant negative mutant that does not bind HIF) and R167W (an inactive mutant that is not dominant negative) were also transfected. Cells were transfected with coding DNA or the empty vector (pcDNA) and incubated for 2 days, then treated with MG115 for 4hrs and harvested. Whole cell extracts were immunoprecipitated with a mixture of monoclonal mouse antibodies directed against the pore and C-terminus of

Eag1, and detected with anti-ubiquitin antibody. Only cells transfected with VHL WT show an enrichment of a 100kDa Eag1 band, while no change was observed in high molecular weight Eag1 (Figure 3.16.

The reverse of this experiment was also performed, precipitating extract with antiubiquitin bound beads and detecting using a polyclonal rabbit antibody against Eag1, but extensive non-specific detection made interpretation of the data extremely difficult (data not shown). 


\subsubsection{In vitro ubiquitylation assay of Eag1 c-terminus}

To further verify whether ubiquitylation is VHL-mediated, an in vitro VHL ubiquitylation assay was performed. Rabbit reticulocyte lysate was mixed either with HIS-tagged Eag1 C-terminus cDNA or without (no DNA). The translated protein was then incubated either without further addition, or with a cocktail containing E1, Ubc3, Ubc5 (both E2 ligases important for the degradation of HIF-1 $\alpha$ ), VHL, and ubiquitin. Immediately after addition of this second cocktail, the translated protein was either immediately denatured and frozen ("0 min") or incubated for an additional 90 minutes ("90 min"). This protein cocktail was then electrophoresed through a 5-15\% gel, transferred, and detected using either an anti-Eag1 polyclonal c-terminus antibody (9391) or an anti-HIS antibody (Figure 3.17).

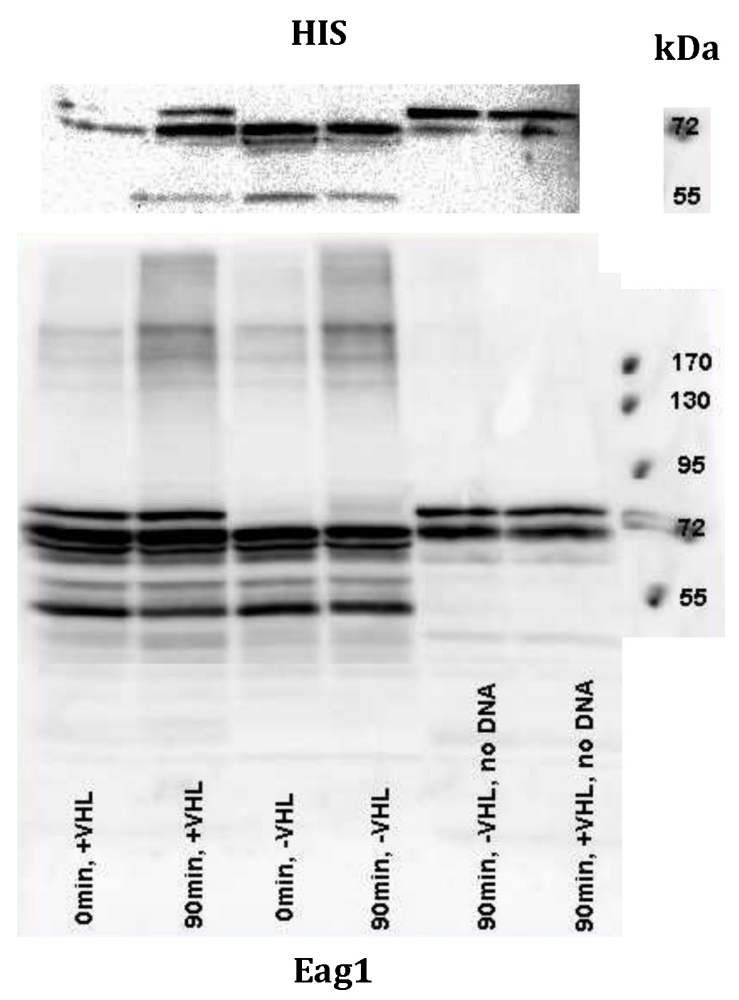

Figure 3.17: in vitro ubiqutylation of Eag1 c-terminus. - Rabbit reticulocyte lysate was treated for 0 or 90 minutes ("0 min", "90 min", respectively) with or without VHL ("-VHL", "+VHL", respectively). Lysate was also pretreated either with Eag1 c-terminus cDNA or without ("no DNA"). Lysate was then detected using anti-HIS antibody (top) or using an anti-Eag1 c-terminus antibody (bottom). 


\section{RESULTS}

A $75 \mathrm{kDa}$ band was observed using both the 9391 and the anti-HIS antibody, an observation that was consistently reflected as this experiment was repeated. Eag1 and HIS detection both suggest that this band is not-specific to Eag1, as the band exists in lanes in which no Eag1 cDNA was added. Most importantly, while a high molecular weight smear was detected above $130 \mathrm{kDa}$ in VHL treated lysate using the 9391 antibody, this signal was not noticeably stronger than that found in lysate not treated with VHL. Furthermore, no high molecular weight signal could be detected using the anti-HIS antibody. If anything conclusions can be made from these results, it is that VHL is not necessary in this system for the ubiquitylation of Eag1. However, it does not preclude the possibility that an E2 other than Ubc3 or Ubc5 is important for VHL-mediated ubiquitylation.

\subsection{Possible Eag1 degradation pathways}

\subsubsection{Eag1 and the proteosome}

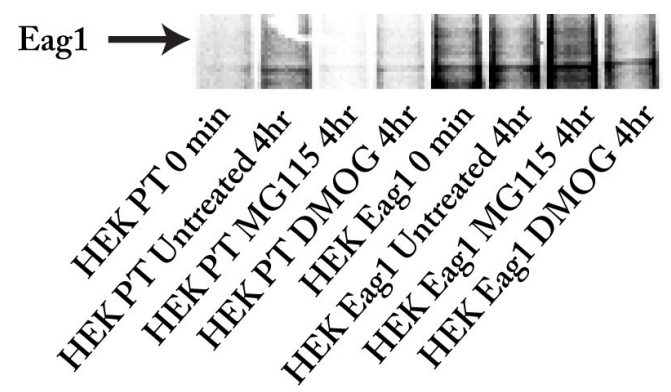

Figure 3.18: $\mathrm{S}^{35}$ labelled Eag1 degradation - A faint double band can be observed in Eag1 expressing cells that is not present in nonEag1 expressing cells. MG115 treatment causes an increase in band intensity as compared to untreated, while DMOG treated cells show an elimination of the Eag1-specific band.
Ubiqutylation is usually, but not always, a signal to target a protein for proteasome-mediated degradation. To investigate this, I instructed a student in patch clamp electrophysiology who compared Eag1 whole cell current density in Clone A cells treated with MG115 and cycloheximide. Cells treated with MG115 for 8 hours showed a similar rescue of cycloheximideinduced current density as treatment with hypoxia or DMOG (Figure 3.19 . left panel). Immunoblot experiments on whole cell extract show a great increase in Eag1 protein after only 4 hours, compatible with the rapid degradation normally associated with ubiquitin-mediated degradation.

A possible interpretation for this MG115/cycloheximide effect could be changes in channel permeability. In order to conclusively determine whether the MG115-mediated 

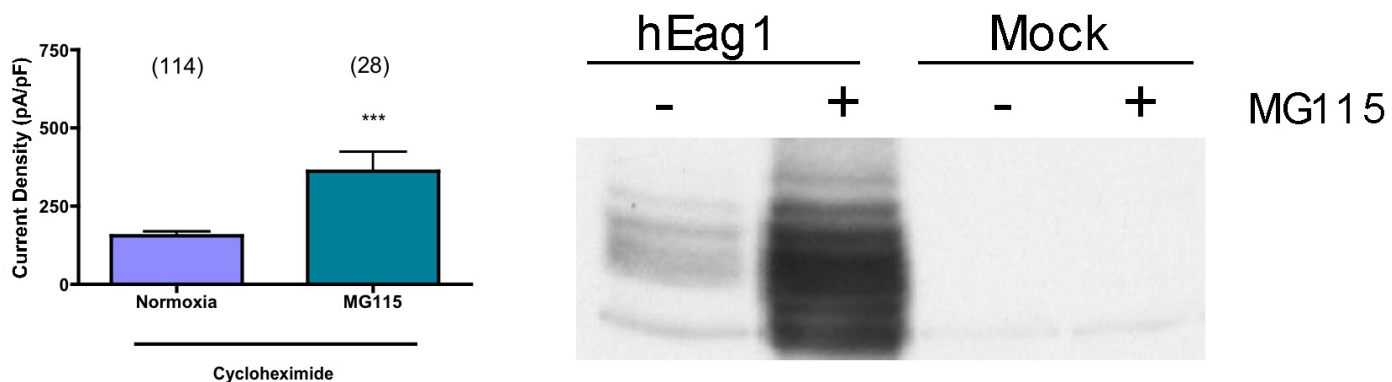

Figure 3.19: Eag1 interaction with the proteasome - (left panel) MG115 (10 $\mu \mathrm{M})$ and cycloheximide $(10 \mu \mathrm{g} / \mathrm{mL})$ treated cells show an enrichment of whole cell current density as measured by patch clamp electrophysiology (right panel). Clone A whole cell extract show an enrichment of Eag1 signal after 4hrs treatment with MG115 $(10 \mu \mathrm{M})$. No signal is detected in mock transfected cells with or without MG115. (Left panel provided by Ye Chen; right panel provided by Dr. Sánchez)

enrichment of Eag1 protein and current density is due to alterations in protein degradation, $\mathrm{S}^{35}$ pulse chase experiments were performed on Clone A cells. Cells were starved of cysteine and methionine for 30 minutes, then supplied with $\mathrm{S}^{35}$ labelled cysteine and methionine for 30 minutes. Cells were subsequently either immediately lysed, or incubated without labelled amino acids for 4 hours in the presence of MG115 or DMOG (Figure 3.18). A faint double band can be observed in HEK-Eag1 cells that is difficult to recognize in HEK-PT cells. Moreover, this double band intensifies upon treatment with MG115, while DMOG treatment reduces the intensity of the Eag1 signal. These results suggest that DMOG treatment enhances Eag1 degradation, rather than inhibits it, a finding at odds with previous results. However, the intensification of an Eag1 signal upon treatment with MG115 is in good agreement with both the electrophysiology and western blot data.

\subsubsection{Eag1 and the lysosome}

Hydrophobic proteins are often degraded in the lysosome, and given the large transmembrane segments of Eag1, I also wanted to see whether blocking the lysosome had any effect on Eag1 expression. Clone A cells were transfected with V5-tagged BACE, a lysosomally degraded protein in neurons. As BACE degradation is blocked upon treatment with the lysosomal blocker chloroquine (CQN), detection of V5-BACE enrichment 


\section{RESULTS}

was used as a positive control. Transfected cells were treated 2 days later with either MG115 or CQN. In both cells transfected and untransfected with BACE, 24 hrs of $200 \mu \mathrm{M}$ CQN treatment induced an enrichment of Eag1 protein, particularly strengthening an $80 \mathrm{kDa}$ band (Figure 3.20). This effect was also observed in cells transfected with BACE and treated with $10 \mu \mathrm{M}$ MG115 for $4 \mathrm{hrs}$, suggesting that BACE expression in some way helps stabilize this product, possibly by interaction with the lysosome.

While it is possible that the MG115 induced expression of BACE-mediated stabilization of the $80 \mathrm{kDa}$ band is artifactual in nature, the CQN enrichment of this band was reproducible and seems to indicate a role for the lysosome in Eag1 expression.

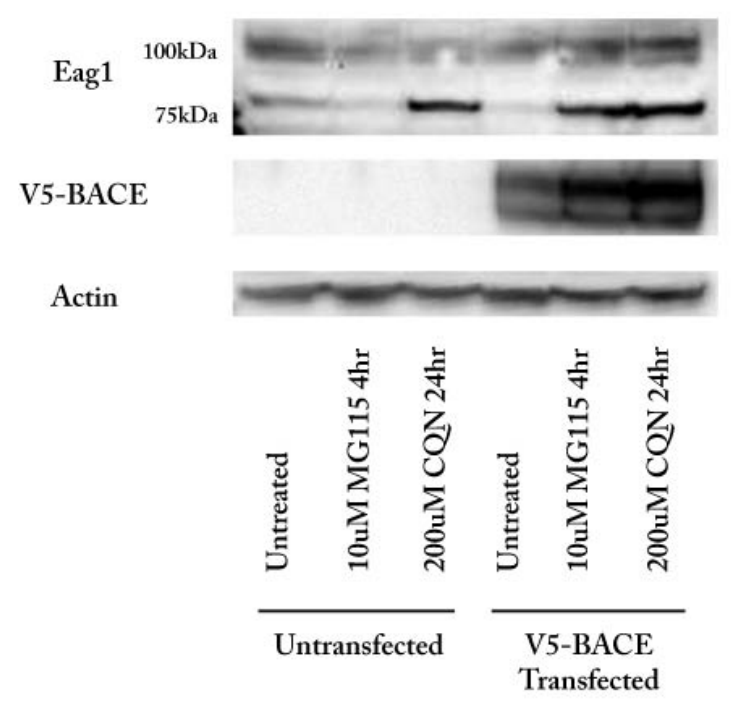

Figure 3.20: Eag1 interaction with the lysosome - Chloroquine $(200 \mu \mathrm{M}, 24 \mathrm{hrs})$ treated cells show an increase in an $80 \mathrm{kDa}$ band which is not observed in untreated cells. This band also appears in MG115 treated cells (10 $\mu \mathrm{M}, 4 \mathrm{hrs})$, although only in those cells transfected with V5-BACE. CQN treated cells show an enrichment in V5-BACE over untreated cells.

\subsection{Eag1 induction of HIF and it's consequences}

\subsubsection{Eag1 expression stabilizes HIF-1}

If Eag1 functionally interacts with components of the HIF-1 degradation pathway, it could affect HIF-1 expression. To investigate this, HIF-1 expression in HEK293 Eag1 Clone A and mock transfected cells were compared after 4 hrs of normoxic (21\% 
$\left.\mathrm{O}_{2}\right)$ or hypoxic $\left(1 \% \mathrm{O}_{2}\right)$ conditions. Initially, this experiment was performed using western blots, but difficulties in finding reliable and clear differences between Eag1 expressing cells and mock-transfected cells led me to examine the expression of HIF using flow cytometry. After treatment, cells were fixed with $4 \%$ paraformaldehyde and permeabilized with $0.6 \%$ saponin. Permeabilized cells were then treated with an antiHIF-1 monoclonal antibody and probed with a Cy5 conjugated secondary antibody.

Because of the sensitivity of the flow cytometry instrument, differences in expression can be quantified and statistically compared. Initial experiments demonstrated that Eag1 expressing cells exhibited an increase in HIF1 under both hypoxic and normoxic conditions (Figure 3.21). However, as Clone A is a monoclonal cell line, increases in HIF stability could be due to clonal insertion into the DNA and not due Eag1 expression. To mitigate this possibility, HIF expression in two additional monoclonal cell lines expressing Eag1 (selected for robustness of Eag1 current as measured via whole cell patch clamp) were compared. All three cell lines were seen to exhibit an increase of $50 \%$ in HIF-specific fluorescence over mock-transfected cells (Figure 3.22 .

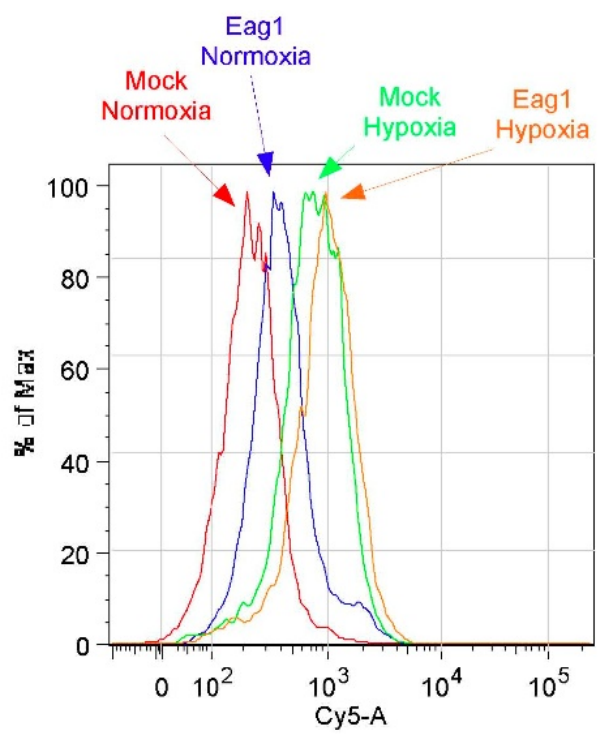

Figure 3.21: HIF-1 changes in Clone A using flow cytometry. - Eag1 expressing cells under normoxia $\left(21 \% \mathrm{pO}_{2}\right.$; blue) show an increase in HIF expression as compared to mocktransfected cells under normoxia (red). Both mock and Eag1 expressing cells under hypoxia $\left(1 \% \mathrm{pO}_{2}\right.$ show more HIF expression under hypoxia, although Eag1 expressing cells (orange) still show an increase over mock (green).

A more relevant assay of HIF expression is to actually measure its activity. After transfecting Clone A or mocktransfected cells with a luciferase vector driven by the HIF-spectific HRE (hypoxia response element) promoter region, cells were either left untreated or exposed to mockhypoxia by treatment with $200 \mu \mathrm{M} \mathrm{CoCl} 2$ for 4 hours. Cells were then lysed and evaluated for luciferase expression using a high-sensitivity luciferase activity assay kit 


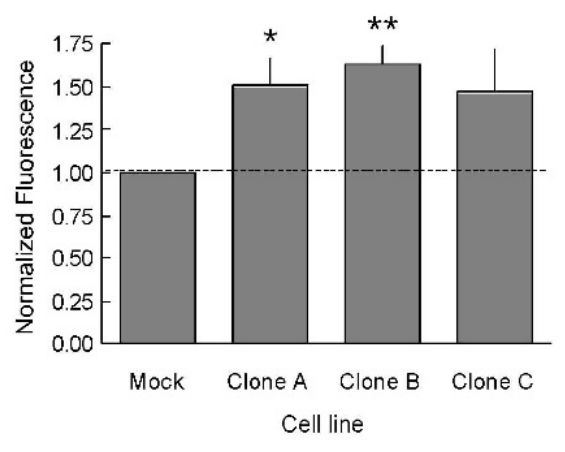

Figure 3.22: HIF-1 changes in three monoclonal Eag1 cell lines. - Three Eag1 expressing cells under normoxia show increases in HIF expression as compared to mocktransfected cells.

(Roche). Under both normoxia and mock-hypoxia conditions, Eag1 expressing cells showed an elevation over mock-transfected cells (Figure 3.23). It is important to note that both mock and Eag1 expressing cells react positively to the presence of chemically induced hypoxia, as indicated by the change in scale between the two graphs. This result shows that the HRE vector responds to HIF activity.
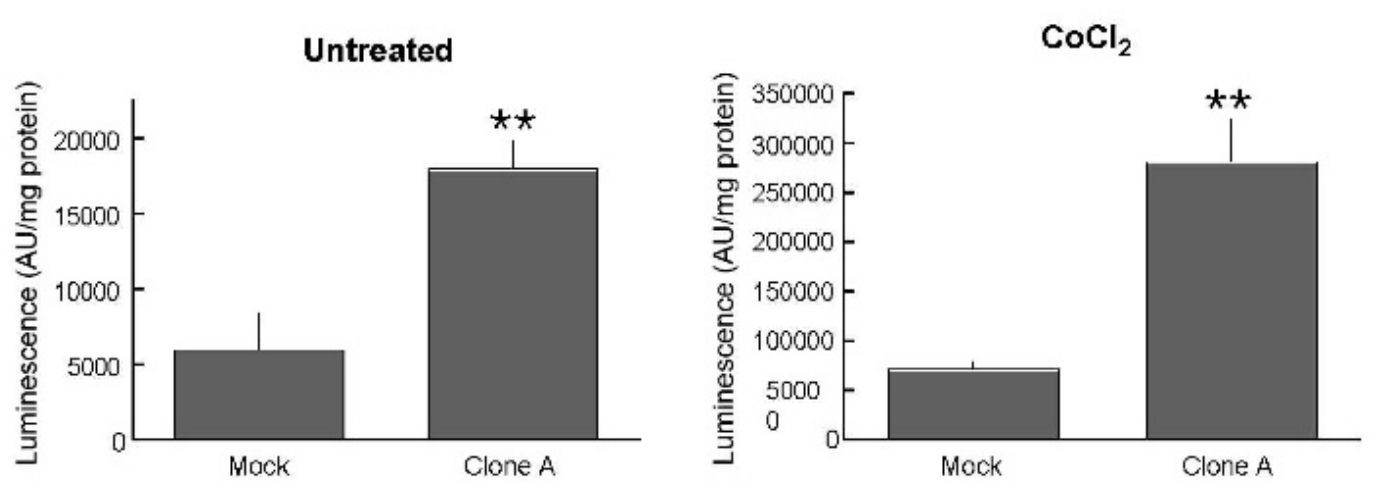

Figure 3.23: HRE response in Eag1 expressing cells. - Eag1 expressing cells show increases in HRE activity under both $21 \% \mathrm{O}_{2}$ (left panel) and $200 \mu \mathrm{M} \mathrm{CoCl}_{2}$ (right panel).

An interesting question is whether the change in HIF expression correlates to a change in oxygen sensitivity - i.e. whether Eag1 expressing cells begin expressing HIF at a higher oxygen concentration than non-Eag1 expressing cells. This can be 
determined by titrating both cell lines with $\mathrm{CoCl}_{2}$, replicating varying atmospheric oxygen concentrations while preventing errors due to changes in transfection efficiency or incubators. After normalizing data to HIF activity in the absence of $\mathrm{CoCl}_{2}, \mathrm{Eag} 1$ expressing cells were observed to show a greater sensitivity to $\mathrm{CoCl}_{2}$ treatment, inducing HIF with as little as $50 \mathrm{uM} \mathrm{CoCl}_{2}$, while mock and untransfected cells both showed no induction of HIF at that concentration (Figure 3.24).

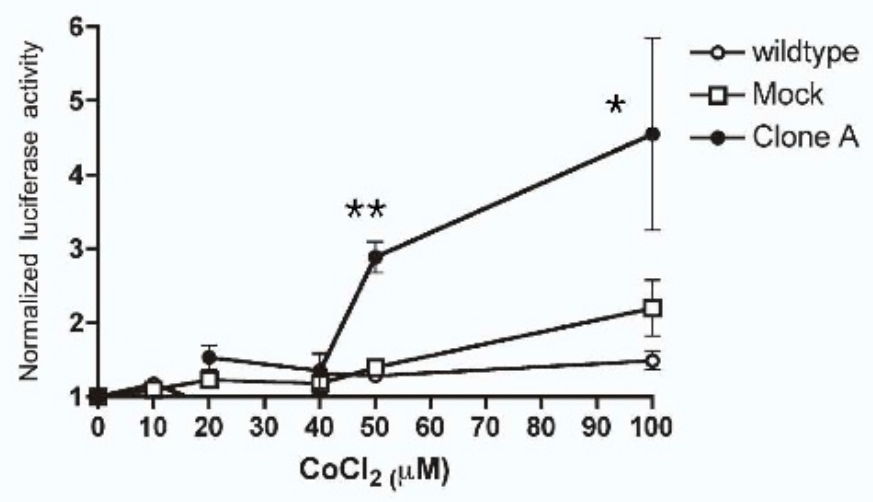

Figure 3.24: Changes in HRE induction in Eag1-expressing cells. - Eag1 expressing cells (black circle) show earlier induction of $\mathrm{HRE}$ activity after treatment with $\mathrm{CoCl}_{2}$ than mock (white square) or untransfected cells (white circle). Data was normalized for each cell line to its own HRE activity in the absence of $\mathrm{CoCl}_{2}(0 \mu \mathrm{M})$.

Because Clone A cells show a greater sensitivity of the HIF system, we expected to find a more dramatic change in HIF expression under mild hypoxia. Clone A or mock transfected cells were treated to $5 \% \mathrm{O}_{2}$ for 4 hours and lysed using a $8 \mathrm{M}$ urea containing buffer to immediately stop all cellular activity, as HIF degradation upon reoxygenation occurs on an order of minutes. Cell extracts were analyzed using western blot and Clone A cells demonstrated a clear increase in HIF expression over mock-transfected cells (Figure 3.25), while under $7 \% \mathrm{O}_{2}$, Eag1 expressing cells showed clear HIF expression while mock-transfected cells did not (data not shown).

If there is a direct correlation between Eag1 expression and HIF-1 (for example, stabilization of HIF via competitive binding to the enzymes that regulate HIF degradation), then targetting Eag1 for knockdown in stably transfected cells should reduce HIF expression in these cells. To examine this possibility, cells were transfected with 


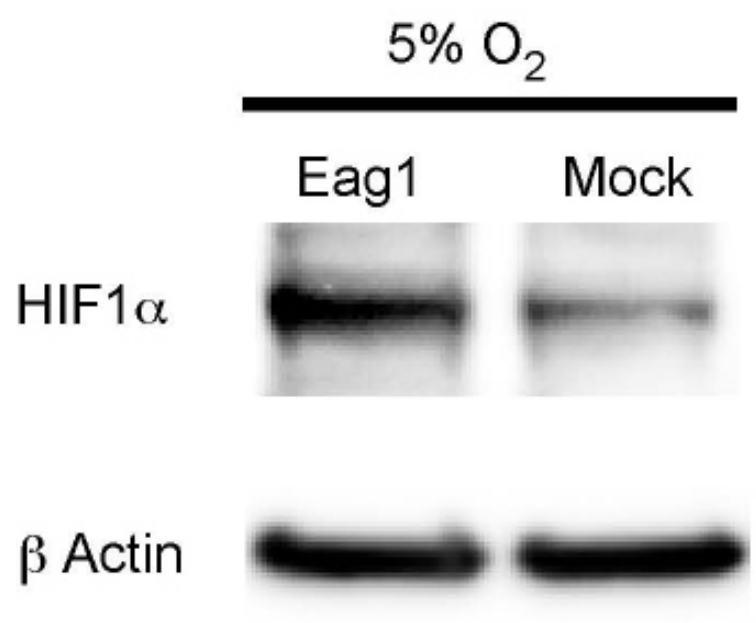

Figure 3.25: HIF expression under mild hypoixa. - Clone A extracts treated with mild hypoxia $\left(5 \% \mathrm{O}_{2}\right)$ showed an increase in HIF expression over mock transfected cells.(Figure provided by Dr. Sánchez)

anti-Eag1 siRNA and probed for HIF expression. Cells were left to incubate for up to 3 days, subjected to $5 \% \mathrm{O}_{2}$ for 4 hours, and lysed. While knocking down Eag1 produced an increase in HIF expression, this did not appear to be a specific effect, as undirected siRNA (Ambion) produced a similar response 2 days after incubation (Figure 3.26).

To further investigate whether this HIF stabilization could be due to an off-target effect of the siRNA, Clone A cells were co-transfected as described earlier with the HRE luciferase vector used previously (3.20) and one of four untargetted siRNAs, including the Ambion negative control used above (Scrambled 1). These values were compared to cells transfected with no siRNA, both with and without treatment of $100 \mu \mathrm{M}$ DMOG for 22 hours (a mild mimicker of hypoxia). Only one scrambled siRNA (\#3) showed a response equivalent to cells transfected without siRNA (Figure 3.27). Troublingly, one of the scrambleds (\#4) evoked an HRE response stronger than mock-hypoxia treated cells.

\subsubsection{Eag1 and VEGF}

Among the many factors influencing angiogenesis, vascular endothelial growth factor (VEGF) appears to be predominant. VEGF has drawn intense attention in the field of 


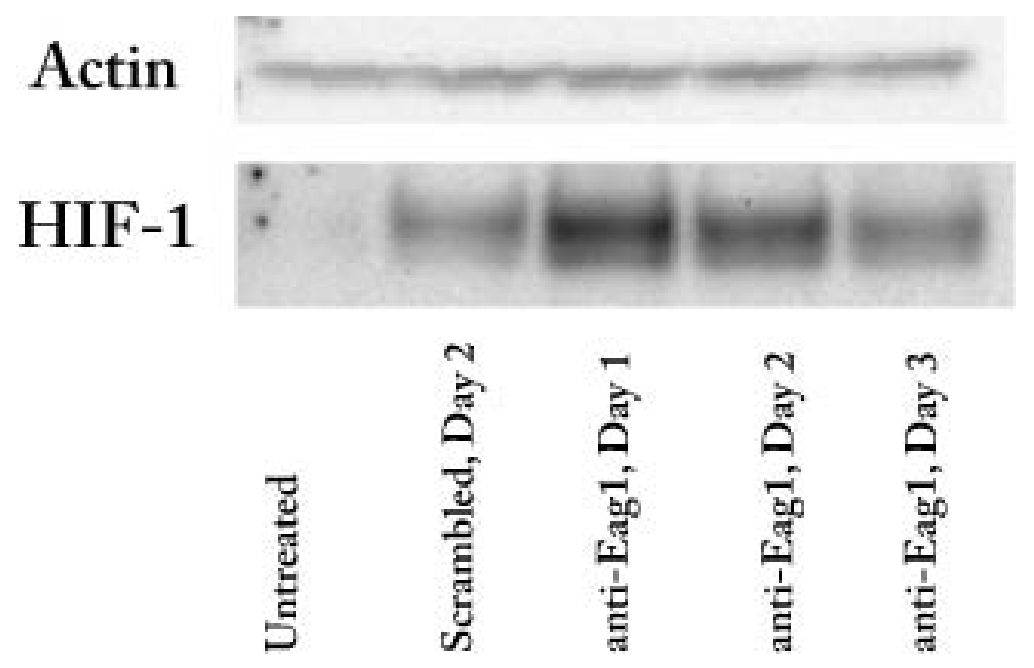

Figure 3.26: Eag1 knockdown influence on HIF-1 expression. - Clone A extracts treated with mild hypoxia $\left(5 \% \mathrm{O}_{2}, 4 \mathrm{hrs}\right) 1,2$, or 3 days after transfection with anti-Eag1 show an increase in HIF expression over untreated cells. A similar result is observed in cells transfected with non-targetting siRNA.

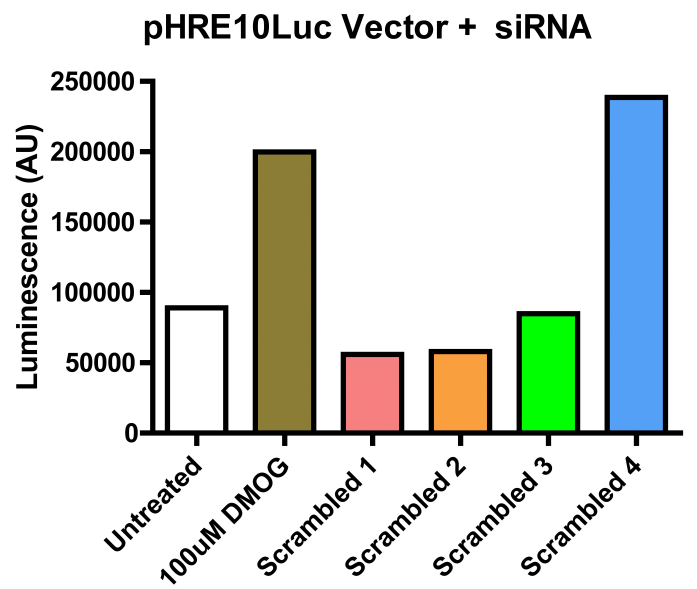

Figure 3.27: Effect of non-targetted siRNA on HIF response. - Clone A extracts were co-transfected with one of four non-targetting siRNA complexes. Three of four show a change in expression of the HRE luciferase reporter vector as compared to cells transfected only with the HRE luciferase reporter vector. As positive control, cells transfected only with the HRE reporter vector were treated with $100 \mu \mathrm{M}$ DMOG. 


\section{RESULTS}

oncology due both to its influence on tumor survival and to its potential use in cancer therapies. Because a direct consequence of HIF-1 activation is almost always increased VEGF secretion, I determined VEGF abundance in the culture supernatant of cells expressing Eag1.

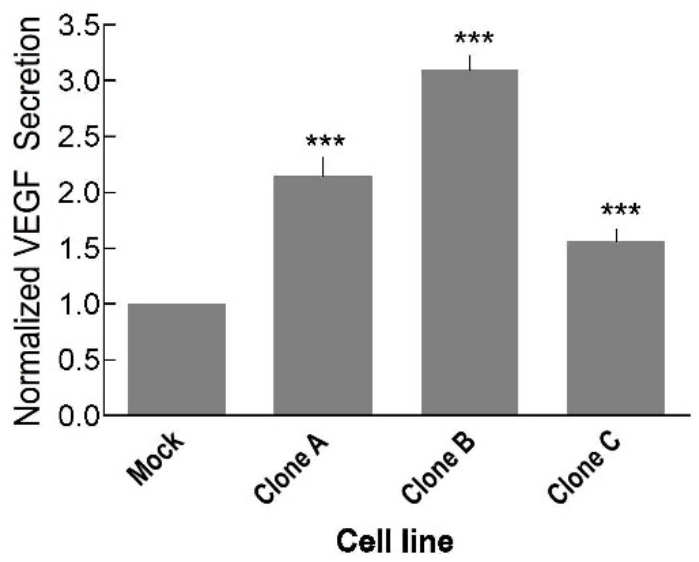

Figure 3.28: VEGF secretion from Eag1 cells - Clones A, B, and C all show more VEGF secretion as measured by ELISA than mock-transfected cells.

Cell culture media for each cell line was replaced and extracted 22 hours later. VEGF secretion was measured and normalized to cell total protein content in three independent clones of the HEK293 cell line stably expressing Eag1 by ELISA (Clones A, B, and C) and compared to mock-transfected cells. All three Eag1 expressing cell lines were found to secrete two to three times more VEGF than the non-transfected control (Figure 3.28).

Because human Eag1 tumorigenic effects have been studied using mouse and hamsterderived tumors, the effects of Eag1 on VEGF secretion was also studied in 3T3 and CHO cells. Both cell lines show an increase in VEGF secretion as compared to wild-type cells (Figure 3.29).

\subsubsection{Tissue consequences of Eag1 expression}

As VEGF is the predominant growth factor in promoting neo-angeogenesis in vivo, we also examined vascularization in tumors derived from SCID mice. Tumor slices were stained with CD31, a marker for endothelial structures, and thus blood vessels. Eag1 expressing tumors were found to contain distinctly more blood vessels as tumors derived 


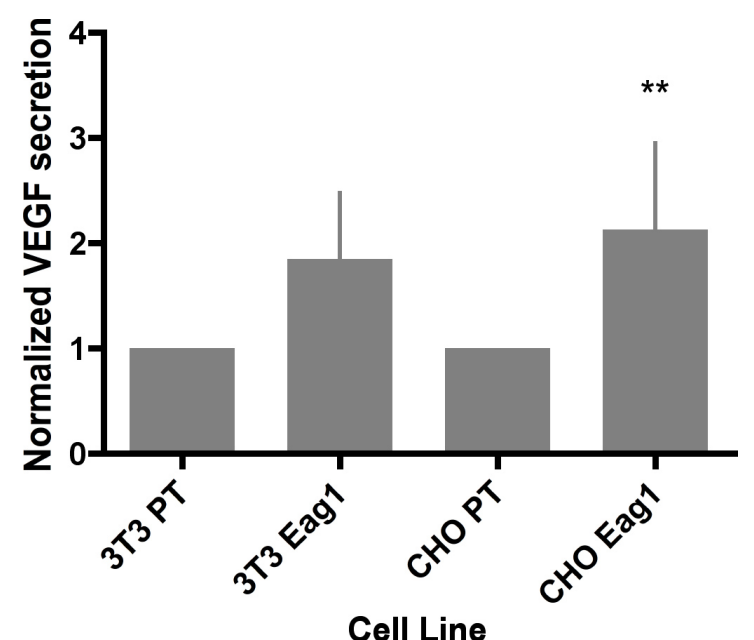

Figure 3.29: Eag1-mediated VEGF secretion in non-human cells. - Both 3T3 and $\mathrm{CHO}$ cells secrete more VEGF when expressing Eag1.

from control cells (Figure 3.30). Quantification of blood vessel surface area found an increase of 2.5 in total blood vessel surface area in Eag1-derived tumors as control tumors (data not shown).

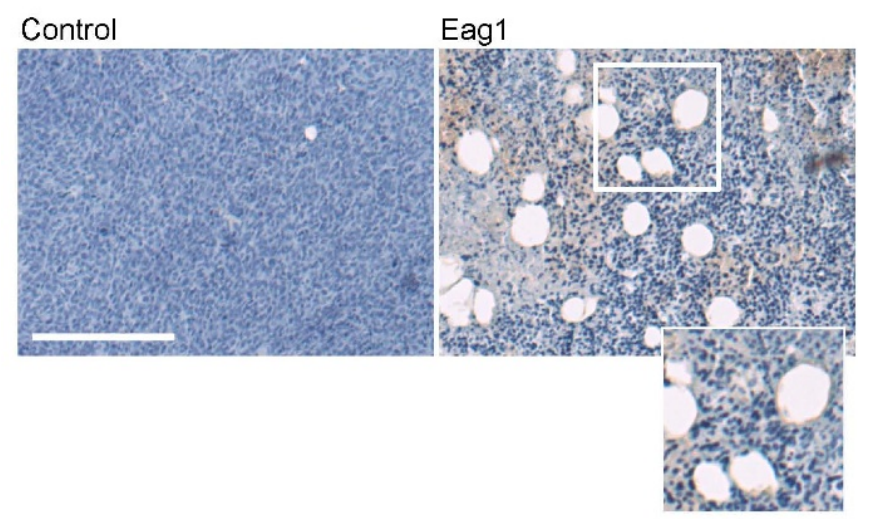

Figure 3.30: Vascular staining of Eag1 and control tumors - Tumors derived from Eag1 cells implanted into SCID mice show more vascularization (right panel) than control (left panel). (Scale Bar: $50 \mu \mathrm{m}$ ) 
3. RESULTS 


\section{4}

\section{Other experiments}

\subsection{Eag1 and mTOR/MAPK}

mTOR (mammmalian target of rapamycin) is a large signalling kinase complex that is a key regulator of mRNA translation by regulating eIF4E phosphorylation. It has been extensively studied, although many of the initial discoveries stem from its name, when it was first discovered that the antifungal and immunosuppresent drug rapamycin inhibited mTOR activity. mTOR inhibition leads to a reduction in protein synthesis, and can also be triggered by hypoxia, starvation of amino acids, and cellular stress. Moreover, a direct link between mTOR activity and HIF-1 $\alpha$ expression has been observed, most likely by translational regulation (for review, see (? )).

MAPK is an important kinase that responds to mitogen signals via PI3K and regulates gene expression, proliferation, and cell survival. Recently, Eag1 expression has been linked to MAPK activity, suggesting a different role for Eag1 in tumorigenesis (70).

\subsubsection{Eag1, HIF, and mTOR}

As mTOR is an important regulator of ER-associated degradation and PI3K activity has been increasingly shown to be regulated by ion channel activity (for example, see (? ? )), we decided to first investigate any possible role mTOR inhibitors might have on Eag1 and HIF activity. To begin, I investigated what the effect of mTOR inhibition would be on HIF expression in mock-transfected cells and cells expressing Eag1. Whole cell extract prepared from cells treated with 200nM rapamycin and mild hypoxia (7\% 


\section{OTHER EXPERIMENTS}

$\mathrm{O}_{2}$ ) were immunoblotted with anti-HIF antibodies. While PT cells showed a decrease in HIF expression after treatment with rapamycin, Eag1 expressing cells showed no such reduction (Figure 4.1).

\section{HIF-1}

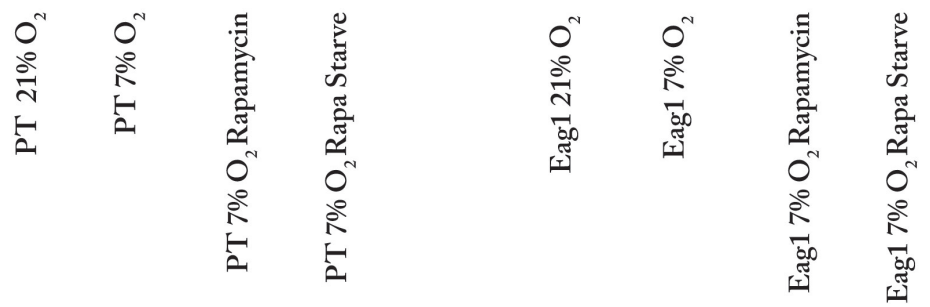

Figure 4.1: Eag1-induced alteration in HIF expression under rapamycin. While mock-tranfected cells (left) show a reduction of $7 \% \mathrm{O}_{2}$-induced HIF stabilization after treatment with 200nM rapamycin for $4 \mathrm{hrs}$, no such reduction is observed in Eag1 expressing cells (right). No similar discrepency is observed in cells further deprived of serum.

Because VEGF secretion is tightly linked to HIF expression, cell culture supernatant was probed for VEGF concentration using ELISA technology as described earlier. Mock-transfected cells show an overall reduction in VEGF secretion when treated with rapamycin for $4 \mathrm{hrs}$ at $7 \% \mathrm{O}_{2}$, an effect which is exacerbated when incubating cells in the absence of serum (Figure 4.2). Conversly, Eag1 expressing cells show no appreciable reduction in VEGF secretion upon treatment with rapamycin, regardless of the presence of serum or not.

\subsubsection{Eag1 expression and MAPK}

To further investigate the role of mTOR in Eag1-expressing cells, we purchased a multiplex antibody cocktail which allows for the probing of multiple phosphorylated proteins on a single membrane (Pathscan Multiplex Western Blot Cocktail I, Cell Signalling Technologies). Cells were cultured with a combination of $7 \% \mathrm{O}_{2}$, serum starvation, and/or 200nM rapamycin. Cells were then lysed, electrophoresed, and transfered to a nitrocellulous membrane for immunoblotting. Upon treatment with the Western Blot Cocktail, two observations were clear: While mock-transfected cells without serum and rapamycin, but with hypoxia, showed no increase in phosphorylated S6 (a marker of 


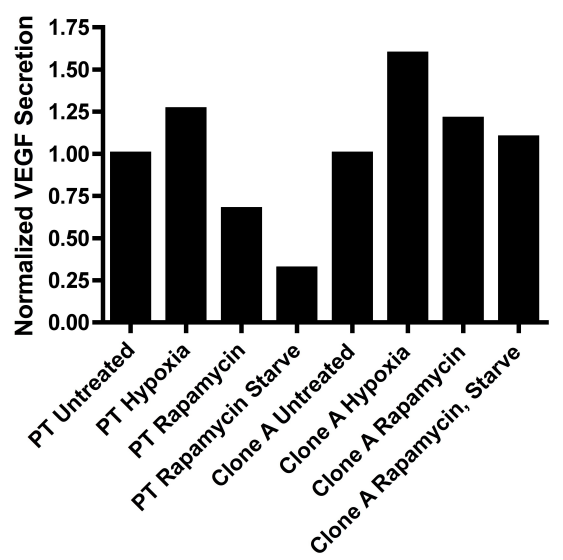

Figure 4.2: Eag1-induced alteration in VEGF secretion under rapamycin. While mock-tranfected cells (left) show a reduction of $7 \% \mathrm{O}_{2}$-induced VEGF secretion after treatment with 200nM rapamycin for 4hrs, no such reduction is observed in Eag1 expressing cells (right). Note that mock-transfected serum deprived cells do not reflect the stabilization of HIF-1 observed in ??.

mTOR activity) (Figure 4.3 lane 6), Clone A cells showed strong phosphorylation of S6 under similar conditions ((Figure 4.4 lane 6). Moreover, Clone A cells showed a strong activation of MAPK in the presence of serum under all conditions, whereas PT cells did not.

\subsubsection{Conclusions}

Interpretation of the finding that Eag1-expressing cells are not as sensitive to rapamycininduced HIF inactivation as mock-transfected cells is difficult in light of the finding that Eag1 expressing cells show an overall increase in HIF expression. There are many possibilities: HIF or Eag1 expression could de-stabilize the mTOR pathway, reducing its influence on protein translation. Eag1 could interact directly upstream of mTOR, perhaps by an interaction with PI3K at the plasma membrane. Or perhaps alteration of MAPK activity affects mTOR activity.

The finding that $\mathrm{S} 6$ activity is not inhibited under hypoxia by serum deprivation suggests an overall robustness in the mTOR pathway, which may or may not be related to MAPK activity. The finding that Eag1-expression induces p38-MAPK activity is not novel, but the signal intensification upon serum deprivation seems a promising 
HEK293 PTracer (mock)

Phospho-Akt

MAPK

Phospho-S6

eIF-4E (loading ctrl)

Hypoxia

Rapamycin (200nM)

FCS

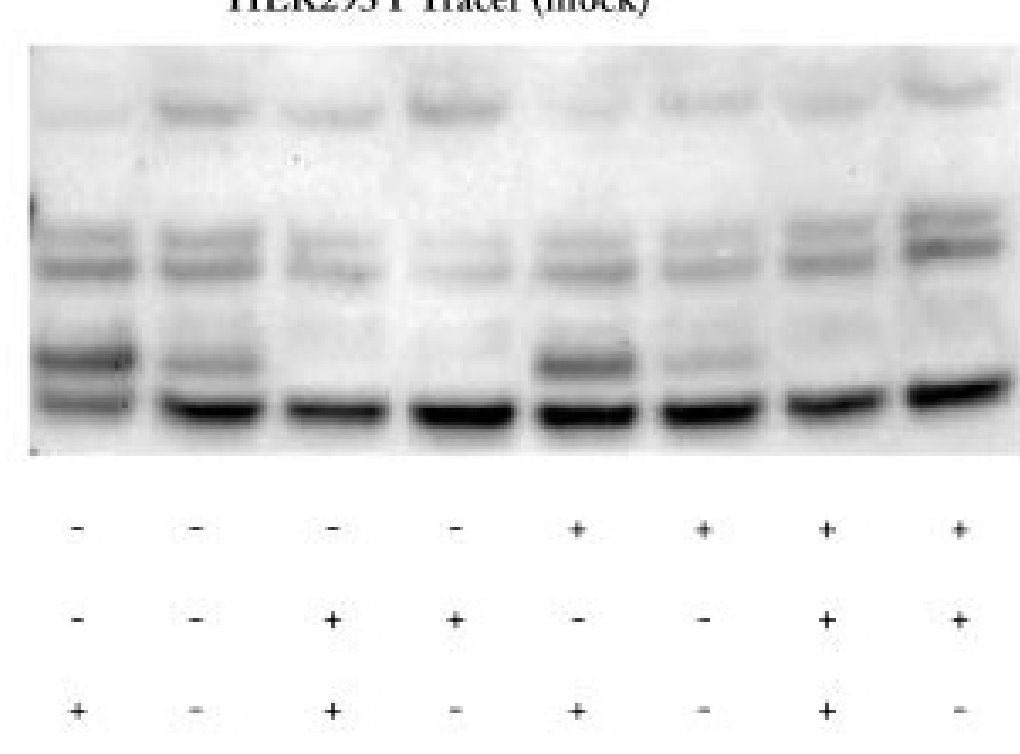

Figure 4.3: HEK PT activation of MAPK/mTOR - Mock-transfected cells exhibit phosphorylated S6 without rapamycin under normoxia, but serum starvation blocks P-S6 under $7 \% \mathrm{O}_{2}$ (lane 6 ). MAPK shows mild activation under all conditions tested.

\section{HEK293 Eag1 Clone A}

Phospho-Akt

MAPK

Phospho-S6 eIF-4E (loading ctrl)

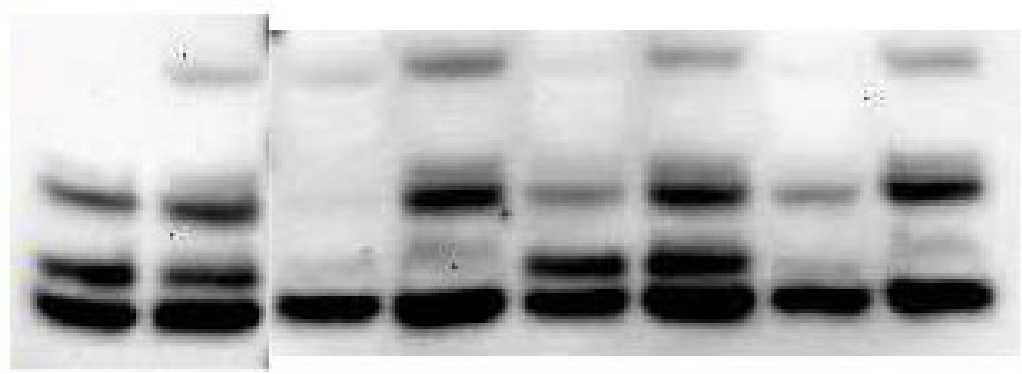

Hypoxia

Rapamycin (200nM)

FCS

Figure 4.4: Eag1 activation of MAPK/mTOR - Mock-transfected cells exhibit phosphorylated $\mathrm{S} 6$ without rapamycin under both normoxia and $7 \% \mathrm{O}_{2}$. MAPK shows strong activation in the presence of serum and mild activation for all other conditions. 
lead. This work is not complete and will require further investigation to determine any Eag1-MAPK-mTOR link.

\section{2 siRNA knockdown of Eag1 current density}

As part of a technical paper on the effects of siRNA knockdown of Eag1 on proliferation, I verified the effects of anti-Eag1 siRNA on current density (22). Cells were transfected as described earlier with anti-Eag1 siRNA and whole-cell current density was measured either $24 \mathrm{~h}$ or $72 \mathrm{~h}$ post-transfection. Anti-Eag1 siRNA treatment completely eliminated Eag1 current density as compared to non-targetted siRNA 24h after transfection (Figure 4.5. left). This effect was completely recovered $72 \mathrm{hrs}$ after transfection (right).

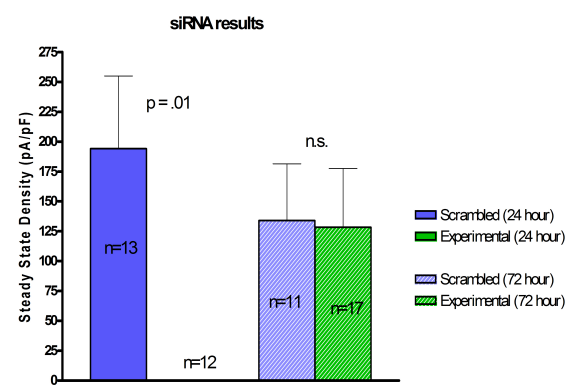

Figure 4.5: Eag1knockdown by siRNA - HEK293 Eag1 clone A cells were transfected with anti-Eag1 siRNA or non-targetting siRNA and Eag1 current density measured using whole cell patch clamp either $24 \mathrm{~h}$ (left) or $72 \mathrm{hr}$ (right) later. $24 \mathrm{~h}$ after transfection, antiEag1 siRNA produced a complete reduction of Eag1 current density, which was completely recovered $72 \mathrm{~h}$ post-transfection.

\subsection{Chemical modification of HERG blockers to reduce channel affinity}

HERG blocking can induce LQTS, a cardiac disorder that can trigger arrhythmia and lead to sudden death (71). Approximately $3 \%$ of all drug prescriptions involve medications that cause LQTS (72). Due to the frequency and severity of this problem regulatory agencies require that every new drug be assessed for its propensity to induce LQTS and measurements of HERG blockage need to be included in the preclinical safety test (73). 


\section{OTHER EXPERIMENTS}

HERG blockers act on the intracellular side of the channel by binding to specific residues (74). Due to the unique molecular features of HERG, many drugs with diverse chemical structures can block this channel (75). Such promiscuous and unpredictable binding of compounds to HERG has frustrated attempts to design drugs that minimise HERG blockage while maintaining activity for the therapeutic target (72). To address this crucial issue, we made a common chemical modification to a HERG blocker that prolongs the QT interval, the antihistamine astemizole (AST) (76). This modification ensured that these drugs remained in the extracellular media.

\subsubsection{NMA block of HERG}

Astemizole (AST) is potent blocker of HERG that has an IC50 in the nano-molar range. By chemically modifying the hydrophobic chemical via $\mathrm{N}$-alkylation to permanently add a positive charge, the new N-methyl-astemizole-iodide (NMA) should lose any affinity for HERG as it would be unable to cross the plasma membrane and reach its intracellular binding site. Stably transfected HEK293-HERG cells were recorded from using whole-cell patch clamp and perfused with either AST or NMA. High concentrations of NMA $(500 \mathrm{nM})$ produced a HERG tail current reduction of only $15 \%$, while substantially lower concentrations $(30 \mathrm{nM})$ of AST produced tail current reduction of $70 \%$ (Figure 4.6). While AST was determined to be a high affinity blocker with an IC50 of approximately 12nM, NMA was classified as a low-affinity blocker with an IC50 of approximately $2 \mu \mathrm{M}$ (Figure 4.6, right).

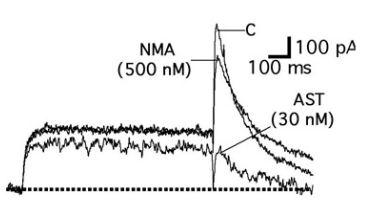

\begin{tabular}{cc}
\hline DRUGS & $\mathrm{IC}_{50}$ HERG $(\mu \mathrm{M})$ \\
\hline AST & 0.012 \\
NMA & 2.025 \\
\hline
\end{tabular}

Figure 4.6: HERG current in response to N-Methyl Astemizole - Left: HERG currents in permanently transfected HEK-293 cells in response to a 1s depolarization to +40 $\mathrm{mV}$ from a holding potential of $70 \mathrm{mV}$, and subsequent return to holding voltage for $0.5 \mathrm{~s}$. The traces represent the steady-state blockage obtained with the indicated concentration of the different blockers; C, Control; AST, Astemizole; NMA, N-Methyl Astemizole. The dashed line indicates the zero current level. Right: Calculated HERG IC50 for AST and NMA. AST exhibits IC50 of 12nM, while NMA has an IC50 of $2 \mu \mathrm{M}$. 


\subsubsection{Conclusion}

$\mathrm{N}$-alkylation is a simple and effective chemical modification to prevent hydrophobic compounds from crossing the plasma membrane and reaching intracellular targets. While this may not be desirable for compounds whose primary targets are intracellular, N-alkylation can help diminish off-target effects and establish new, more specific compounds. 
4. OTHER EXPERIMENTS 


\section{5}

\section{Discussion}

Despite several studies implicating Eag1 ectopic expression in many cancer cell lines and primary tumors $(21,22,23 ; 29 ; 30,31 ; 32)$, it is only recently that evidence for the mechanism of Eag1s contribution to tumorigenesis has begun to come to light (33). This work describes a candidate mechanism for the extraordinary rate of expression of Eag1 in human tumors by stabilizing HIF expression and promoting VEGF secretion and angiogenesis. It seems likely that this pro-oncogenic behavior is due to a direct and functional interaction between Eag1 and the important elements of the HIF degradation pathway; PHD, VHL, and the proteasome. Such an interaction could lead to an inhibition of HIF binding to these regulators, causing a competitive inhibition of HIF degradation. In effect, Eag1 binding to PHD and VHL stabilize HIF and promote angiogenesis.

\subsection{Eag1 physically and functionally interacts with prolyl hydroxylases}

Eag1 current density is strongly inhibited upon protein synthesis inhibition, an effect that is counter-acted by incubation under hypoxia (3.2). This effect is not observed in the absence of cycloheximide 3.1, and occurs in cells expressing the channel under the control of a non-native promoter, strongly indicating a post-translational, oxygen dependent modification of Eag1 or its interacting partners. This modification cannot depend on HIF-1 $\alpha$, because the inhibition of protein synthesis by cycloheximide blocks the activity of HIF-1 $\alpha$ (77). Inhibition of prolyl-hydroxylase (by DMOG) mimics the 


\section{DISCUSSION}

effects of hypoxia, while its stimulation by ascorbate produces a further reduction of current density under normoxia (3.3). Therefore, the changes observed in Eag1 current density are independent of HIF-1, but dependent on prolyl-hydroxylase activity. No changes in cellular redox potential is observed after Eag1 expression, indicating that the prolyl hydroxylases should not act in an unusual way in these cells (3.4).

While no interaction was observed in a yeast 2-hybrid screen between the $\mathrm{N}$-terminus and any of the PHDs, the C-terminus was found to interact with both PHD1 and PHD3 3.5, 3.6, 3.7). Interestingly, PHD3 has a much greater affinity for oxygen than its constituitively expressed cousin PHD2, hydroxylating HIF-1 $\alpha$ at lower concentrations of oxygen. Such an interaction presumably results in proline hydroxylation in Eag1, but the absence of mass spectrometry analysis prevents us from answering this question. The poorly-described PHD1 also interacts with Eag1, indicating there may be a novel role for this otherwise unknown protein.

In contrast, Eag1 also precipitates together with PHD2 (3.9) in vivo, a finding at odds with the yeast 2-hybrid screen. Moreover, siRNA-mediated knockdown of PHD2 both reduces high molecular weight Eag1 (??) and reduces Eag1-ubiquitin immunoprecipitation (3.15). Finally, block of PHD by DMOG or $1 \% \mathrm{O}_{2}$ further reduces Eag1-ubiquitin immuno-precipitation, an observation that reflects the greater efficacy of chemical inhibition. Together, these data suggest that PHD2 expression influences Eag1 ubiquitylation, a finding in contrast to data observed in the yeast-two-hybrid screen. This conflict between in vitro and in vivo binding results can be reconciled by recognizing that the in vitro assay is performed using fragments of the Eag1 protein.

$75 \%$ of the Eag1 protein exists in intracellular domains, many of which are directly involved in binding soluble proteins in the intracellular space. Moreover, both the N(78) and the C-terminus have been identified as important for gating of Eag1 due to cross-domain interactions between the two termini (79). Expressing only one terminus could destroy interactions with partners such as PHD2 if this binding depended on conformational states. That an $\mathrm{N}$ - and C-terminus interaction exists suggests that Eag1 must serve a secondary (and probably tertiary, quarternary, etc) function to the its canonical role as a conductor of ions, as many much smaller channels function perfectly well in the absence of large intracellular domains.

One candidate domain for Eag1-PHD interaction is the LXXLAP putative PHD binding region, just outside the PAS domain on the N-terminus. This motif is highly 
conserved and is critical for recognition of HIF- $1 \alpha$ by PHD. Mutants of this motif in Eag1 show a remarkable change in the normal Eag1 cellular localization (unpublished data, personally communicated by Dr. Pardo).

The gene egl-9 in Caenorhabditis elegans was also identified as an ortholog of PHD. The mutant of egl-9 leads to egg-laying deficiency phenotypes (80), a similar phenotype of which can be obtained by examining mutants of the eag ortholog egl-2 (81). While similar phenotypes can arise from completely independent causes, a direct relationship between egl-9 and egl-2 could explain these similarities.

\subsection{Eag1 physically and functionally interacts with VHL}

While there is no VHL interaction with the N-terminal of Eag1 in vitro (3.10), one surprising result was the pulldown of Eag1 with VHL in a PHD-independent manner (3.11). This binding would be expected if the domain of VHL which modifies Eag1 is not the only domain that binds Eag1. For example, binding of VHL to the Cterminus and gating of Eag1 could swing VHL into position to modify another protein domain which might normally be inaccessible. VHL and Eag1 co-immunoprecipitate together in both heterologous and native cells 3.12 , indicating an in vivo interaction. These results are also in good agreement with a description of a functional relationship between VHL expression and Eag1 current (68).

A VHL interaction would most likely lead to the ubiquitylation of Eag1, as VHL's primary role as an E3 ubiquitin ligase is well established (55). Ubiquitin-Eag1 coimmunoprecipitation is enriched after transfection of VHL cDNA 3.16) and is reduced after siRNA mediated knockdown of VHL (3.15). The VHL dominant negative mutant does not have a dramatic influence on Eag1 ubiquitylation, implying that any role for VHL in Eag1 ubiquitylation is not dependent on the residue that eliminates HIF binding in VHL. Unfortunately, showing VHL-mediated ubiquitylation in vitro was impossible due to non-specific antibody recognition (3.17). It seems likely that VHL acts as an E3-ubiquitin ligase for Eag1, but such a statement cannot be conclusively made. 


\section{DISCUSSION}

\subsection{Eag1 is ubiquitylated and is proteasomally degraded.}

The increase of Eag1 current density and protein (3.19) upon proteasomal block is most likely related directly to the ubiquitylation of Eag1 (3.13), as ubiquitin is often a degradation signal. MG115 also enriches an Eag1-compatible double band in a $\mathrm{S}^{35}$-labeled pulse chase degradation assay (3.18). Curiously, blocking PHD activity using DMOG enhances Eag1 degradation, suggesting that PHD-mediated ubiquitylation does not direct the channel to the proteasome. This could be explained if Eag1 underwent two regulatory steps in the system I used - an non-specific ERAD pathway associated with eliminating overexpressed proteins and a more specific PHD-mediated ubiquitylation system.

Ubiquitylation of ion channels is thought to usually target the protein for internalization and subsequent intracellular targets, often not for the purposes of degradation, but rather for recycling or modification (for review, see (66)). Ubiquitylation can also drive transmembrane proteins to be degraded, either by the proteasome or the lysosome. The epithelial $\mathrm{Na}^{+}$channel $(\mathrm{ENaC})$ is enriched both by blockers of the lysosome and proteasome and by mutants of target lysine residues (82).

The strong enrichment of a $80 \mathrm{kDa}$ implies that some part of Eag1 is lysosomally degraded or targetted for cleavage by a protein that is lysosomally degraded. Because the antibody used targets the C-terminal of Eag1, this increase can be explained by several possibilities:

- Cleavage occurs on the N-terminal, cleaving approximately 20kDa from the larger protein

- Lysosomal block enriches binding of a undescribed binding partner to the Cterminus of Eag1

- Lysosomal block induces expression of a recently described $80 \mathrm{kDa}$ soluble splice variant implicated in the MAPK and PKA/PKC signalling pathways (83).

Whether this lysosomal effect is related to the proteasomal degradation will be an interesting question for future experiments. 


\subsection{Eag1 stabilizes HIF-1}

The very high frequency of ectopic expression of Eag1 in primary tumors (30; 32) indicates that Eag1 expression confers a selective advantage to tumor cells under conditions that are common to the majority of neoplasms. Such a common condition could be hypoxia. The major immediate consequence of hypoxia is HIF-1 up-regulation, which is widely accepted as a hallmark of cancer physiology, both from our understanding of the tumor micro-environment and the role of HIF-1s target genes in cell proliferation, survival and angiogenesis (84). The fact that the strongest difference observed in HIF expression between Eag1 and mock-transfected cells occurs at $\mathrm{O}_{2}$ ranges that are compatible with the $\mathrm{EC}_{50}$ of the PHDs (3.25) suggests that this effect is PHD mediated, a finding which is supported by the interactions between Eag1 and PHD. An even more compelling argument for the stabilization of HIF being a direct consequence of Eag1 expression would have been found in a rescue of the HIF stabilization upon treatment with anti-Eag1 siRNA, but the stabilization of HIF by non-targetting siRNA made this experiment technically difficult $3.26,3.27$.

\subsection{Eag1 expression induces VEGF secretion and neo- angiogenesis}

The Eag1-driven increase in VEGF secretion (3.28) and in angiogenesis in vivo (3.30) provide a likely and novel explanation for the oncogenic potential of Eag1. The ectopic expression of Eag1 could thus have far reaching effects, as the increased secretion of growth factors and angiogenic-signaling molecules would have lasting effects within the local tumor micro-environment. It has been further reported that the related channel HERG also influences VEGF secretion in glioblastoma cell lines, although the mechanism by which this occurs remains unclear (85).

\subsection{Eag1 may promote tumorigenesis via competitive in- hibition}

Our proposed hypothesis to explain the role of Eag1 in tumorigenesis is that ectopically expressed Eag1 interacts with prolyl-hydroxylase, sequestering active sites of the 


\section{DISCUSSION}

enzyme that would normally recognize and hydroxylate HIF-1 $\alpha$. Hydroxylated Eag1 would then be recognized by pVHL, further interfering with the normal degradation pathway of HIF-1 $\alpha$ and competing with its ubiquitylation. To support this model, we provide evidence for direct interactions between Eag1 and three of the four core components of the HIF-1a degradation system: pVHL, ubiquitin, and the proteasome. Indirect evidence presented here shows that the final core component, prolyl hydroxylase, clearly has some role in modulating Eag1 current density, but difficulties in purifying transmembrane proteins preclude direct evidence for the hydroxylation of Eag1. This hypothesis is in good agreement with the report that a tagged destrution domain of HIF-1 $\alpha$ can induce tumorigenic phenotype through competition with HIF-1 for active sites in pVHL (86).

An alternative model would simply involve physical sequestration of one or more of the PHDs by Eag1. Such a model has already been proposed for the intracellular domain (ICD) of Notch and the HIF activity regulator Factor Inhibiting HIF (FIH) (87). FIH shows a greater affinity for the ICD of Notch than it does for HIF, causing co-localization of the regulator together with the transmembrane protein. Such a model could be applied as well to Eag1 and PHD/VHL - the transmembrane protein preventing regulatory activity simply by virtue of its binding to PHD/VHL. This binding would most likely also convey some manner of regulatory function onto the channel. pH dependent sequestration of VHL to the nucleolus has been proposed as a mechanism to regulate HIF expression (88), demonstrating that simply examining whether a protein is expressed may obfuscate the full implications of a protein-protein interaction. (89; 90$)$

\subsection{Eag1 and the brain}

While much of this work has been focused on the role of Eag1 in tumorigenesis, these results have broader implications for the role of Eag1 in the brain. The best characterized Eag1-expressing cell line is the neuroblastoma cell line SHSY-5Y. Neuroblastomas originate from the nervous system, and SHSY-5Y cells can be differentiated upon application of retinoic acid into cells indistinguishable from neurons. Upon differentiation, these cells lose measurable Eag1 current, although that is no indication for the loss of Eag1 protein (28). Recent reports have identified Eag1 channel localization to the 
somatodendritic region of neurons (89; 90), although unpublished electron microscopy data refutes that claim (personal communication from Dr. Pardo). In fact, no successful recordings of Eag1 current in neurons have been reported to date, suggesting that functional Eag1 channels are normally restricted to the synapse.

VHL expression can also induce differentiation in SHSY-5Y cells (60) and differentiation provides protection from hypoxic injury (91). Finally, neurons in PHD3 knockout mice show reduced apoptosis and impaired development in certain areas of the brain (92). Given the influence of PHD and VHL on Eag1, it is possible that these effects are Eag1 mediated, although the influence of HIF on fundamental cellular gene expression cannot be understated.

Other ion channels and hypoxia have fallen under examination in recent years. The ATP-sensitive potassium channel $\mathrm{K}_{A T P}$ has been shown to also serve some protection from brain hypoxia (93) while hypoxia drives HIF and VHL regulated expression of $\mathrm{Ca}^{2+}$-activated potassium channels (94).

Oxygen regulation itself is critically important to the proper functioning of the brain. The brain uses more oxygen than any other organ, utilizing $20 \%$ of all oxygen consumed by the body (95). While the developing brain is resistant to hypoxic insult (96), neurons deprived of oxygen die within minutes and strokes are one of the leading causes of death and disability in the developed world. HIF-1 and it's products EPO (97) and VEGF (98, 99) have all been implicated in a role of neuroprotection following hypoxic insult.

\subsection{Eag1 likely promotes tumorigenesis via interaction with intracellular domains}

How does Eag1 promote oncogenesis? This is the fundamental question this work seeks to address, yet in the end this question remains fundamentally unanswered. We know that Eag1 expression promotes HIF and VEGF expression and increased angiogenesis in tumors, and that VHL and PHD functionally interact with intracellular domains. We also know that Eag1 and Eag2 show the greatest dissimilarity in these intracellular regions, and it has been established that these domains interact with one another. Unfortunately, we cannot conclude directly with this information that the interaction between Eag1, PHD, and VHL are sufficient or necessary for tumorigenesis, or that the 


\section{DISCUSSION}

interaction leads to HIF-1 expression. The two observations that Eag1 interacts with PHD/VHL and Eag1 induces HIF remain, for now, unrelated.

Upon reflection, this finding is not unsurprising - Eag1 is an extremely large protein with multiple functions and binding sites. Eag1 has now been shown to interact with CamK2, activated calmodulin, Camguk/CASK adapter protein, PHD, VHL, epsin, and ubiquitin, in addition to its putative primary role as a conductor of ions. Moreover, Eag1 expression seems to influence MAPK/mTOR pathways in as of yet undetermined ways (?? 4.2, 4.4). It seems likely that the network of signalling and trafficking pathways impacting Eag1 interfere with one another, obfuscating any single pathway's contribution to Eag1-promoted tumorigenesis. Any interaction between Eag1-promoted HIF-expression is most likely not the only driver of oncogenesis, but rather is due to a multitude of factors that influence one another.

Hypotheses to explain how ion channels could contribute to tumor formation have largely been restricted to analysis of changes in ion permeability, such as changes in cell volume due to changes in osmotic pressure or the effects of hyper- or de-polarization on the cell membrane. Yet these speculations have been unable to address the fundamental question of why only some channel appear to contribute to oncogenesis. Eag1 is an excellent example of this quandry - it's close cousin Eag2 is $70 \%$ identical and has a nearly identical electrophysiological profile, yet its expression has not been linked to any cancer.

Increasingly, binding partners and modulators of Eag1 are being identified, partners whose function in cells regulate the normal cellular mechanisms for controlling metabolism, cell proliferation, and cell death. These partners represent a novel noncanonical contribution of an ion channel to tumor formation through pathways at least partly independent of the putative primary function of Eag1 as an ion channel. While non-canonical protein functions have been proposed as relevant for the phenotypic changes induced in heterologous systems (e.g. (100; 101)), the evidence presented here supports their role in native systems as well. In fact, the primary role of Eag1 may well be as a voltage sensor, transducing membrane voltage into intracellular signaling, a role compatible with the observations made in this work. 


\section{6}

\section{Materials \& methods}

\subsection{Cell Culture}

Cell lines were obtained from DSMZ (Germany) and maintained according to the instructions of the provider. For transfected cells, the selection compound Zeocin (Calya) was added to the culture medium at $3 \mathrm{~g} / \mathrm{mL}$. Hypoxia culturing (1\% or $3 \% \mathrm{O} 2$ ) was performed by $\mathrm{N} 2$ injection in an oxygen-controlling chamber (Labotec). Rapamycin was obtained from MobiTec.

\subsection{Flow Cytometry}

Cells were incubated for 20 hours in the absence of selective pressure, washed twice with cold PBS and fixed for 30 minutes $4 \%$ p-formaldehyde at 4 C. Fixed cells were scraped form the flask and washed 3 times and permeabilized with $0.3 \%$ saponin for 15 minutes at room temperature. The cells were then incubated with $10 \%$ BSA, $0.15 \%$ saponin for 15 minutes to block non-specific binding, and incubated for 2 hours with HIF- $1 \alpha$ antibody (AB463, BD Biosciences) diluted 1:100 in $0.1 \%$ saponin $/ 2 \%$ BSA in PBS (PBS-SB) at $4 \mathrm{C}$. Cells were washed 3 times with PBS-SB, and then incubated 1.5 hours with a Cy5-conjugated anti-mouse antibody diluted 1:5000 in PBS-SB. Cells were again washed 3 times and assessed for Cy5 fluorescence using a BD FACSAria flow cytometer (Becton Dickinson, Heidelberg, Germany) with 633nm laser excitation. Forward and side scatter were used to detect and discard cell fragments and doublets. Data are presented as average fluorescence. 


\section{MATERIALS \& METHODS}

\subsection{Electrophysiology}

hEag1a-transfected HEK293 and SHSY-5Y neuroblastoma cells were plated on polyL-lysine-coated glass coverslips in Petri dishes and allowed to attach overnight. Cells were then left untreated or treated with some combination of $10 \mu \mathrm{g} / \mathrm{mL}$ cycloheximide (Sigma), 1mM dimethyoxalylglycine (Frontier Scientific, Europe), or 2mM ascorbate (Merck) for 6-8 hours. Coverslips were then removed from the dish and used for electrophysiological measurements.

Electrophysiological recordings were performed in the whole cell configuration of the patch clamp (102) using an EPC9 amplifier and Pulse software (HEKA). Currents were filtered at $10 \mathrm{KHz}$ and digitized at $50 \mathrm{KHz}$. Patch pipettes were pulled from Corning \#0010 glass (World Precision Instruments) to resistances of 1-2 M. Solutions for HEK293 cells contained (mM) Internal: $100 \mathrm{KCl}, 45 \mathrm{NMDG}, 5$ 1,1bis(O-aminophenoxy)ethane-N,N,N,N-tetracetic acid (BAPTA), 5 EGTA, 1 MgCl2, 10 HEPES ph7.4; external: $160 \mathrm{NaCl}, 2.5 \mathrm{KCl}, 2$ CaCl2, 1 MgCl2, 8 Glucose, 10 HEPES, pH 7.4; for SHSY-5Y, internal: $115 \mathrm{KCl}, 1 \mathrm{MgCl} 2,5$ EGTA, 5 BAPTA, 15 sucrose, , 10 HEPES pH 7.2 and external: $140 \mathrm{NaCl}, 2.5 \mathrm{KCl}, 2 \mathrm{CaCl} 2,1 \mathrm{MgCl} 2,8$ Glucose, 10 HEPES, pH 7.4.

We used the automated capacity compensation of the amplifier to estimate series resistance, which was compensated to $85 \%$, and cell capacity. In HEK293 cells, the amplitude of the heterologous Eag1 current is robust enough to mask endogenous currents almost completely (see for example (103)). To determine Eag1 current amplitude, we applied a conditioning pulse to $-100 \mathrm{mV}$ for $1500 \mathrm{~ms}$ to slow down the activation of Eag1, and the outward currents were then elicited by a square depolarization to +40 $\mathrm{mV}$ for $500 \mathrm{~ms}$. We measured the mean steady state current between 350 and $450 \mathrm{~ms}$ after the start of depolarization and subtracted from this value the current amplitude between 7 and $13 \mathrm{~ms}$ after the start of depolarization (9).

For measurements of hERG in HEK293 cells, Astemizole (Sigma) or N-MethylAstemizole (? ) were used.

\subsection{Transient transfection}

Cells to be transfected were first counted using a Neubauer chamber. $1 \times 10^{6}$ cells were plated in $6 \mathrm{~cm}$ petri dishes and cultured for 48 hours to allow cells to firmly 
attach. Lipofectamin 2000 (Invitrogen) and either cDNA or siRNA was incubated in Optimem per the manufacturer's direction. Cells were incubated at $37 \mathrm{C}$ for $4 \mathrm{hrs}$ in Lipofectamin/nucleic acid mixture, then subjected to a media change. Activity was assayed 2 days post-transfection.

$4 m u g$ cDNA was transfected per dish, and 25nM anti-Eag1 siRNA or 50nM of other siRNA was transfected per dish. PHD2 and PHD3 siRNA sequences are described in (51), anti-Eag1 siRNA in (22), and anti-HIF and anti-VHL sequences were purchased from Dharmacon. V5-BACE was obtained from Dr. Christine von Arnim (104) and VHL, Y98H VHL, PHD2, PHD3, and H196A PHD3 were obtained from Prof. Dr. Katschinski.

\subsection{VEGF ELISA}

Mock-transfected, Clone A, Clone B, and Clone C HEK293 cells were counted and plated at the same density in $25 \mathrm{~cm} 2$ flasks. Flasks were cultured overnight with medium containing $3 \mathrm{~g} / \mathrm{mL}$ Zeocin, then media was changed and cultured for 20 hours without selection pressure. Cell culture supernatant was removed and centrifuged to remove cell particulates and detached cells, then assayed for secreted VEGF (Quantikine VEGF ELISA assay kit, R\&D Systems). Cells in the flask were stained with propidium iodide and counted using a flow cytometer.

\subsection{Immunoprecipitation and western blot}

At the end of the trestments described in the text, cells were washed twice with PBS, scraped, centrifuged at $600 \mathrm{xg}$, and resuspended 3 volumes of lysis buffer (mM: 50 Tris $\mathrm{HCl} \mathrm{pH} \mathrm{7.4,} 300 \mathrm{NaCl}, 5$ EDTA, 1\% Triton x-100 containing protease inhibitor cocktail (Roche). After $30 \mathrm{~min}$ incubation, cells were centrifuged (14000 xg $15 \mathrm{~min}$ ) and the supernatant was used as total cell extract. Protein concentration was determined using BCA (Pierce).

Immunoprecipitation was achieved by incubation of $500 \mathrm{~g}$ of the protein extract with either $1 \mathrm{~g}$ anti VHL (BD Pharmingen) or $2 \mathrm{~g}$ anti Eag1 monoclonal antibody mixture. Immunocomplexes were pulled down using $20 \mathrm{~L}$ protein $\mathrm{A} / \mathrm{G}$ agarose (pre-blocked with $0.1 \%$ BSA). Precipitated agar beads were washed three times with lysis buffer 


\section{MATERIALS \& METHODS}

containing $0.1 \%$ triton and once with PBS. Ubiquitylated proteins were purified using the Ubiquitinated proteins enrichment kit (Calbiochem), following the manufacturers protocol.

Protein extracts were separated by gradient SDS-PAGE (either 38 or $412 \%$ ) and transferred to nitrocellulose membranes. Membranes were blocked with $0.1 \%$ casein (Roche Applied Science) and incubated with the corresponding antibody. Antibody against HIF $1 \alpha$ (BD Transduction Laboratories) and ubiquitin (P4D1, Cell Signalling) was used at $0.51 \mathrm{~g} / \mathrm{ml}$ overnight at $4 \mathrm{C}$ in a humidified chamber. Antibody against Eag1 (9391, (105)), V5 (Santa Cruz), VHL (BD Pharmigen) or actin were incubated for $1 \mathrm{hr}$ at room temperature. After washing and incubation with appropriate peroxidase-labeled secondary antibody, blots were developed using Millipore Immobilon system. Signals were detected in a Bio-Rad Chem-Doc luminescence detection system.

For HIF $1 \alpha$ detection, cells were lysed in $10 \mathrm{mM}$ Tris- $\mathrm{HCl} \mathrm{pH}$ 6.8, 1\% SDS, $5 \mathrm{mM}$ dithiothreitol, Protease Inhibitor Mixture (Roche Applied Science), and $8 \mathrm{M}$ urea and to minimize HIF degradation, homogenized using an UltraTurrax device, centrifuged (14,000 x g $15 \mathrm{~min})$, and the supernatant was used as total cell extract. Protein concentration was determined using BCA (Pierce).

Eag1-ubiquitin immunopreciptitation was performed as above, but cell lysate was supplemented with 10mM N-ethylmaleimide (NEM, Sigma) and was stored overnight at -80 C. After protein concentration determination, lysate was cleared of non-specific binding using Protein-G conjugated magnetic beads. Lysate was then incubated with shaking at $4 \mathrm{C}$ overnight with $2 m u g$ anti-Eag1 monoclonal antibody mixture.

\subsection{In vitro transcription-translation (IVTT) and ubiqui- tylation assay}

$1.5 \mu \mathrm{g}$ of hEag1 cDNA was transcribed and translated using Promega TNT T7 IVTT system per manufacturer's instructions. A master mix of $50 \mathrm{mM}$ Tris pH7.6, $5 \mathrm{mM}$ $\mathrm{MgCl}_{2}, 1 \mathrm{mM}$ ATP, $0.6 \mathrm{mM}$ DTT, $2.5 \mu \mathrm{g} / \mu \mathrm{L}$ ubiquitin, $1 \mu \mathrm{M}$ ubiquitin-aldehyde, 20 $\mathrm{mM}$ Creatine Phosphate, $0.24 \mu \mathrm{g} / \mu \mathrm{L}$ Creatine Kinase, and $25 \mu \mathrm{M}$ MG132 was prepared and diluted to 28:72.

+VHL extracts were treated with $.6 \mathrm{ng} / \mathrm{uL}$ E1-Ligase, $3.9 \mathrm{ng} / \mu \mathrm{L}$ Ubc3, $3.9 \mathrm{ng} / \mu \mathrm{L}$ Ubc5 and $7 \mu \mathrm{L}$ of recombinant His-VHL while -VHL were diluted further with $\mathrm{H}_{2} \mathrm{O}$. 


\subsection{Radioactive labelling}

$2 \times 10^{6}$ HEK293 cells were plated in $6 \mathrm{~cm}$ petri dishes. Cells were washed once with DMEM media with 10\% dialyzed FCS lacking Methionine and Cysteine (starvation media), then starved for 15 minutes. Dishes were then treated with $10 \mathrm{muCi}$ of EasyTag Express Protein Labeling Mix (Perkin Elmer) for 15 minutes, then washed with warm PBS and incubated in DMEM/F12 with 10\% FCS. Cells to be lysed were washed once in ice cold PBS with 10mM NEM and lysed as above. SDS-PAGE gels were dryed using Gel-Dry (Invitrogen) and $\mathrm{S}^{35}$-activity assayed using a Fuji Pictography 3000 detector

\subsection{Mouse model}

MDA-MB-435S cells (8x106) were implanted into the flank of 8-week-old female scid mice (Taconic). Treatment started after the tumors reached a size of $2 \mathrm{~mm}$ in diameter, daily via an oral feeder. Body weight and tumor size were measured every 2 days. The same operator always measured the tumors. Astemizole was prepared as stock solution (50 mg/ml) in DMSO and diluted in PBS prior to administration. As a positive control, $5 \mathrm{mg} / \mathrm{kg}$ cyclophosphamide was administered to the animals using the same protocol.

\subsection{Luciferase assay}

Mock-transfected and Clone A cells were counted and plated at the same density in 6-well plates. Cells were then transfected using Lipofectamine 2000 in Optimem with Bartons HRE vector for $4 \mathrm{~h}$, after which the medium was changed to normal growth medium. Luminescence was assayed using a Luciferase Reporter Gene Assay from Roche Applied Science.

\subsection{Inmunohistochemistry}

Formalin-fixed and paraffin-embedded tumor sections were deparaffinized and rehydrated in a series of xylol and ethanol solutions. Antigen retrieval was performed in a microwave oven in $10 \mathrm{mM}$ citrate buffer $(\mathrm{pH}$ 6.0) for 15 min. Slides were incubated overnight in a humidified chamber at $4 \mathrm{C}$ with anti CD34, anti VEGF receptor, antiFactor VIII (all from Abcam) or anti-CD31 antibodies (Santa Cruz Biotechnology) 
and immunoreactivity was detected using the Envision Peroxidase System and DAB (DAKO). Sections were counterstained with hematoxylin and thereafter dehydrated and mounted in xylol-based mounting medium. The quantification of vascular surface was performed by a blinded operator using ImageJ software on 25 high power fields (400x) from each sample acquired. 


\section{References}

[1] J W Warmke And B Ganetzky. A family of potassium channel genes related to eag in Drosophila and mammals. Proc Natl Acad Sci U S A, 91(8):3438-3442, 1994 Apr 12. 1

[2] C F Wu, B Ganetzky, F N Haugland, and A X Liu. Potassium currents in Drosophila: different components affected by mutations of two genes. Science, 220(4601):1076-1078, 1983 Jun 3. This is a test. 1

[3] A Bruggemann, L A Pardo, W Stuhmer, and O Pongs. Ether-a-go-go encodes a voltage-gated channel permeable to $\mathrm{K}+$ and $\mathrm{Ca} 2+$ and modulated by cAMP. Nature, 365(6445):445-448, 1993 Sep 30. 1

[4] J Ludwig, R Weseloh, C Karschin, Q Liu, R Netzer, B EnGeland, C Stansfeld, and O Pongs. Cloning and functional expression of rat eag2, a new member of the ether-a-go-go family of potassium channels and comparison of its distribution with that of eag1. Mol Cell Neurosci, 16(1):59-70, 2000 Jul. 1 4

[5] M J Saganich, E Machado, and B Rudy. Differential expression of genes encoding subthresholdoperating voltage-gated $\mathrm{K}+$ channels in brain. $J$ Neurosci, 21(13):4609-4624, 2001 Jul 1. 1 4

[6] S Martin, C Lino de Oliveira, F Mello de Queiroz, L A Pardo, W Stuhmer, and E Del Bel. Eag1 potassium channel immunohistochemistry in the CNS of adult rat and selected regions of human brain. Neuroscience, 155(3):833-844, 2008 Aug 26. 1

[7] K S COLE and J W MOORE. Potassium ion current in the squid giant axon: dynamic characteristic. Biophys J, 1:1-14, 1960 Sep. 1] 2

[8] Marc Jenke, Araceli Sanchez, Francisco Monje, Walter Stuhmer, Rudiger M Weseloh, and Luis A Pardo. Cterminal domains implicated in the functional surface expression of potassium channels. EMBO $J, 22(3): 395-403,2003$ Feb 3. 1

[9] J Ludwig, H Terlau, F Wunder, A Brüggemann, L A Pardo, A Marquardt, W Stühmer, and O Pongs. Functional expression of a rat homologue of the voltage gated either á go-go potassium channel reveals differences in selectivity and activation kinetics between the Drosophila channel and its mammalian counterpart. EMBO J, 13(19):4451-8, Oct 1994. 252 


\section{REFERENCES}

[21] L A Pardo, D del Camino, A Sanchez, F Alves, A Bruggemann, S BeCKh, AND W Stuhmer. Oncogenic potential of EAG K $(+)$ channels. $E M B O J, \mathbf{1 8}(20): 5540-5547$, 1999 Oct 15.3443

[22] Claudia Weber, Fernanda Mello de Queiroz, Bryan R Downie, Arnt Suckow, Walter Stuhmer, and Luis A PARDO. Silencing the activity and proliferative properties of the human EagI Potassium Channel by RNA Interference. J Biol Chem, 281(19):1303013037, 2006 May 12. 3394353

[23] H Ouadid-Ahidouch, X Le Bourhis, M Roudbaraki, R A Tolllon, P Delcourt, and N Prevarskaya. Changes in the $\mathrm{K}+$ current-density of MCF-7 cells during progression through the cell cycle: possible involvement of a h-ether.a-gogo $\mathrm{K}+$ channel. Receptors Channels, $\mathbf{7}(5): 345-356,2001.343$

[24] O Gavrilova-Ruch, K Schonherr, G Gessner, R Schonherr, T Klapperstuck, W Wohlrab, and S H Heinemann. Effects of imipramine on ion channels and proliferation of IGR1 melanoma cells. J Membr Biol, 188(2):137-149, 2002 Jul 15. 3

[25] David Gomez-Varela, Esther Zwick-Wallasch, Hendrik Knotgen, Araceli Sanchez, Thore Hettmann, Dmitri Ossipov, Rudiger. Weseloh, Constanza Contreras-Jurado, Mike Rothe, Walter Stuhmer, and Luis A Pardo. Monoclonal antibody blockade of the human Eag1 potassium channel function exerts antitumor activity. Cancer Res, 67(15):7343-7349, 2007 Aug 1. 3

[26] WHO. Cancer Fact Sheet July 2008. 3

[27] Bernard W Stewart and P Kleihues. World cancer report. IARC Press, Lyon, 2003. 3

[28] R Meyer and S H Heinemann. Characterization of an eag-like potassium channel in human neuroblastoma cells. J Physiol, 508 ( Pt 1):49-56, 1998 Apr 1. 348

[29] R Meyer, R Schonherr, O Gavrilova-Ruch, W Wohlrab, And S H Heinemann. Identification of ether a go-go and calcium-activated potassium channels in human melanoma cells. $J$ Membr Biol, 171(2):107-115, 1999 Sep 15. 343

[30] Fernanda Mello de Queiroz, Guilherme Suarez-Kurtz, Walter Stuhmer, and Luis A Pardo. Ether a go-go potassium channel expression in soft tissue sarcoma patients. Mol Cancer, 5:42, 2006. 44 4347

[31] Luz Maria Barajas farias, Deysi Bermudez Ocana, Lorenza Diaz, Fernando larrea, Euclides Avila-Chavez, adriana Cadena, luz Maria Hinojosa, Gerardo lara, Luis Alberto Villanueva, Carlos Vargas, Elizabeth Hernandez-Gallegos, Ignacio Camacho-Arroyo, Alfonso Duenas-Gonzalez, Enrique Perez-Cardenas, Luis A Pardo, Angelica Morales, Lucia Taja-Chayeb, Juan Escamilla, Carmen Sanchez-Pena, and Javier Camacho. Ether a go-go potassium channels as human cervical cancer markers. Cancer Res, 64(19):6996-7001, 2004 Oct 1. 443

[32] Bernhard Hemmerlein, Rudiger M Weseloh, Fernanda Mello de Queiroz, Hendrik Knotgen, Araceli Sanchez, Maria E Rubio, Sabine Martin, Tessa Schliephacke, Marc
Jenke, Walter Stuhmer, and Luis A Pardo. Overexpression of Eag1 potassium channels in clinical tumours. Mol Cancer, 5:41, 2006. 44 4347

[33] BR Downie, A Sanchez, H Knotgen, C Contreras-Jurado, M Gymnopoulos, C Weber, W Stuhmer, and La Pardo. Eag1 expression interferes with hypoxia homeostasis and induces angiogenesis in tumors. $J$ Biol Chem, 2008 Oct 16. 443

[34] M J Saganich, E Vega-Saenz de Miera, M S Nadal, H Baker, W A Coetzee, and B Rudy. Cloning of components of a novel subthreshold-activating $\mathrm{K}(+)$ channel with a unique pattern of expression in the cerebral cortex. $J$ Neurosci, 19(24):10789-10802, 1999 Dec 15. 4

[35] Roland Schonherr, Guido Gessner, Karsten Lober, and Stefan H Heinemann. Functional distinction of human EAG1 and EAG2 potassium channels. FEBS Lett, 514(2-3):204-208, 2002 Mar 13. 4

[36] U R Jewell, I Kvietikova, A Scheid, C Bauer, R H WENGER, AND M GASSMANN. Induction of HIF-1alpha in response to hypoxia is instantaneous. FASEB $J$, 15(7):1312-1314, 2001 May. 4.

[37] B H Jiang, G L Semenza, C Bauer, and H H Marti. Hypoxia-inducible factor 1 levels vary exponentially over a physiologically relevant range of $\mathrm{O} 2$ tension. Am J Physiol, 271(4 Pt 1):C1172-80, 1996 Oct. 5

[38] G L Wang and G L Semenza. Desferrioxamine induces erythropoietin gene expression and hypoxiainducible factor 1 DNA-binding activity: implications for models of hypoxia signal transduction. Blood, 82(12):3610-3615, 1993 Dec 15. 5

[39] G L Semenza and G L Wang. A nuclear factor induced by hypoxia via de novo protein synthesis binds to the human erythropoietin gene enhancer at a site required for transcriptional activation. $\mathrm{Mol}$ Cell Biol, 12(12):5447-5454, 1992 Dec. 5

[40] G L Wang and G L Semenza. General involvement of hypoxia-inducible factor 1 in transcriptional response to hypoxia. Proc Natl Acad Sci U S A, 90(9):4304-4308, 1993 May 1. 5

[41] Edurne Berra, Emmanuel Benizri, Amandine Ginouves, Veronique Volmat, Daniele Roux, and Jacques PouysseGUR. HIF prolyl-hydroxylase 2 is the key oxygen sensor setting low steady-state levels of HIF1alpha in normoxia. EMBO J, 22(16):4082-4090, 2003 Aug 15. 5

[42] Jianhe Huang, Quan Zhao, Sharon M Mooney, and FRANK S LEE. Sequence determinants in hypoxiainducible factor-1alpha for hydroxylation by the prolyl hydroxylases PHD1, PHD2, and PHD3. $J$ Biol Chem, 277(42):39792-39800, 2002 Oct 18. 5

[43] K Tanimoto, Y Makino, T Pereira, and L Poellinger. Mechanism of regulation of the hypoxiainducible factor-1 alpha by the von HippelLindau tumor suppressor protein. EMBO J, 19(16):4298-4309, 2000 Aug 15. 5

[44] R K Bruick and S L McKnight. A conserved family of prolyl-4-hydroxylases that modify HIF. Science, 294(5545):1337-1340, 2001 Nov 9. 5 
[45] M Ivan, K Kondo, H Yang, W Kim, J Valiando, M Ohн, A Salic, J M Asara, W S Lane, and W G Jr Kaelin. HIFalpha targeted for VHL-mediated destruction by proline hydroxylation: implications for $\mathrm{O} 2$ sensing. Science, 292(5516):464-468, 2001 Apr 20. 5

[46] P JahkKola, D R Mole, Y M Tian, M I Wilson, J Gielbert, S J Gaskell, H F Hebestreit, M MukherJi, C J Schofield, P H Maxwell, C W Pugh, and P J Ratcliffe. Targeting of HIF-alpha to the von Hippel-Lindau ubiquitylation complex by O2-regulated prolyl hydroxylation. Science, 292(5516):468-472, 2001 Apr 20. 5

[47] Gisela D'Angelo, Eric Duplan, Nicole Boyer, Paul Vigne, and Christian Frelin. Hypoxia up-regulates prolyl hydroxylase activity: a feedback mechanism that limits HIF-1 responses during reoxygenation. $J$ Biol Chem, 278(40):38183-38187, 2003 Oct 3. 5

[48] Maija Hirsila, Peppi Koivunen, Volkmar Gunzler, Kari I KIVIRIKKo, AND JohanNa MYLlyhaRJu. Characterization of the human prolyl 4-hydroxylases that modify the hypoxia-inducible factor. $J$ Biol Chem, 278(33):30772-30780, 2003 Aug 15. 5

[49] David R Mole and Peter J Ratcliffe. Cellular oxygen sensing in health and disease. Pediatr Nephrol, 23(5):681-694, 2008 May. 6

[50] H YANG AND W G KAELIN, JR. Molecular pathogenesis of the von Hippel-Lindau hereditary cancer syndrome: implications for oxygen sensing. Cell Growth Differ, 12(9):447-55, Sep 2001. 6

[51] Jens Köditz, Jutta Nesper, Marieke Wottawa, Daniel P Stiehl, Gieri Camenisch, Corinna Franke, Johanna MylLYhaRJu, Roland H Wenger, and DÖRThe M Katschinski. Oxygen-dependent ATF-4 stability is mediated by the PHD3 oxygen sensor. Blood, 110(10):36107, Nov 2007. 553

[52] Sandra Barth, Jutta Nesper, Philippe A Hasgall, Renato Wirthner, Katarzyna J Nytko, Frank Edlich, Dörthe M Katschinski, Daniel P Stiehl, Roland H Wenger, and Gieri Camenisch. The peptidyl prolyl cis/trans isomerase FKBP38 determines hypoxia-inducible transcription factor prolyl-4-hydroxylase PHD2 protein stability. Mol Cell Biol, 27(10):3758-68, May 2007. 5

[53] Sandra Barth, Frank Edlich, Utta BerchnerPfannschmidt, Silke Gneuss, Gunther Jahreis, Philippe A Hasgall, Joachim Fandrey, Roland H Wenger, and Gier Camenisch. HIF prolyl-4-hydroxylase PHD2 protein abundance depends on integral membraneanchoring of FKBP38. J Biol Chem, Jun 2009 5

[54] Von Hippel E. Ueber eine sehr seltene Erkrankung der Netzhaut. Albrecht von Graefes Arch Ophthal, 59:83-106, 1904. 7

[55] M E Cockman, N Masson, D R Mole, P Jahkkola, G W Chang, S C Clifford, E R Maher, C W Pugh, P J RatClifFe, AND P H MAXWELl. Hypoxia inducible factoralpha binding and ubiquitylation by the von Hippel-Lindau tumor suppressor protein. $J$ Biol Chem, 275(33):25733-25741, 2000 Aug 18. 745
[56] P H Maxwell, M S Wiesener, G W Chang, S C Clifford, E C Vaux, M E Cockman, C C Wykoff, C W Pugh, E R Maher, and P J Ratcliffe. The tumour suppressor protein VHL targets hypoxia-inducible factors for oxygen-dependent proteolysis. Nature, 399(6733):271-275, 1999 May 20. 7

[57] Jung-Hyun Min, Haifeng Yang, Mircea Ivan, Frank Gertler, William G Jr Kaelin, and Nikola P Pavletich. Structure of an HIF-1alpha -pVHL complex: hydroxyproline recognition in signaling. Science, 296(5574):1886-1889, 2002 Jun 7. 7

[58] Wai-Ching Hon, Michael I Wilson, Karl Harlos, Timothy D W Claridge, Christopher J Schofield, Christopher W Pugh, Patrick H Maxwell, Peter J Ratcliffe, David I Stuart, and E Yvonne Jones. Structural basis for the recognition of hydroxyproline in HIF-1 alpha by pVHL. Nature, 417(6892):975-978, 2002 Jun 27. 7

[59] Haifeng Yang, Yoji Andrew Minamishima, Qin Yan, SuSanne Schlisio, Benjamin L Ebert, Xiaoping Zhang, Liang Zhang, William Y Kim, Aria F Olumi, and William G KAELIN, JR. pVHL acts as an adaptor to promote the inhibitory phosphorylation of the NFkappaB agonist Card9 by CK2. Mol Cell, 28(1):1527 , Oct 2007. 7

[60] Yoshihide Tanaka, Hiroshi Kanno, Mari Dezawa, Toshiro Mimura, Atsuhiko Kubo, and Isao Yamamoto. The role of von Hippel-Lindau protein in the differentiation of neural progenitor cells under normoxic and anoxic conditions. Neurosci Lett, 383(1-2):2832, 2005 Jul 22-29. 749

[61] M S O'Reilly, L Holmgren, C Chen, and J Folkman. Angiostatin induces and sustains dormancy of human primary tumors in mice. Nat Med, 2(6):689-92, Jun 1996. 7

[62] J FOLKMAN. What is the evidence that tumors are angiogenesis dependent? $J$ Natl Cancer Inst, 82(1):4-6, Jan 1990. 7

[63] R Mahajan, C Delphin, T Guan, L Gerace, and F MelCHIOR. A small ubiquitin-related polypeptide involved in targeting RanGAP1 to nuclear pore complex protein RanBP2. Cell, 88(1):97-107, Jan 1997. 7

[64] S Kumar, Y YOSHIDA, AND M NODA. Cloning of a cDNA which encodes a novel ubiquitin-like protein. Biochem Biophys Res Commun, 195(1):393-9, Aug 1993. 7

[65] T Kamitani, K Kito, H P Nguyen, and E T Yeh. Characterization of NEDD8, a developmentally downregulated ubiquitin-like protein. J Biol Chem, 272(45):28557-62, Nov 1997. 7

[66] Alessandra D'Azzo, Antonella Bongiovanni, and TomMASO NASTASI. E3 ubiquitin ligases as regulators of membrane protein trafficking and degradation. Traffic, 6(6):429-441, 2005 Jun. 846

[67] VAN G Wilson and Germán Rosas-ACosta. Wrestling with SUMO in a new arena. Sci STKE, 2005(290):pe32, Jun 2005. 8 


\section{REFERENCES}

[68] Hidetoshi Murata, Nobuyoshi Tajima, Yoji Nagashima, Masahiro Yao, masaya Baba, Masayuki Goto, Susumu Kawamoto, Isao Yamamoto, Kenji OKuda, and Hiroshi KANNO. Von Hippel-Lindau tumor suppressor protein transforms human neuroblastoma cells into functional neuron-like cells. Cancer Res, 62(23): 7004-7011, 2002 Dec 1. 81745

[69] Invitrogen. alamarBlue - Rapid and Accurate Cell Health Indicator 14

[] Bradly G Wouters, Twan van den Beucken, Michael G Magagnin, Marianne Koritzinsky, Diane Fels, and ConSTANTinos Koumenis. Control of the hypoxic response through regulation of mRNA translation. Semin Cell Dev Biol, 16(4-5):487-501, 2005 Aug-Oct.

[70] Andrew P Hegle, Daniel D Marble, and Gisela F Wilson. A voltage-driven switch for ion-independent signaling by ether-a-go-go $\mathbf{K}+$ channels. Proc Natl Acad Sci U S A, 103(8):2886-2891, 2006 Feb 21. 35

[1] J Wu, W-G Ding, H Matsuura, K Tsuji, W-J Zang, and $M$ HORIE. Inhibitory actions of the phosphatidylinositol 3-kinase inhibitor LY294002 on the human Kv1.5 channel. Br J Pharmacol, 156(2):377-87, Jan 2009.

[] Michael L Ko, Kuinuan Jian, Liheng Shi, and Gladys Y-P Ko. Phosphatidylinositol 3 kinase-Akt signaling serves as a circadian output in the retina. $J \mathrm{Neu}$ rochem, 108(6):1607-20, Mar 2009.

[71] Michael C Sanguinetti and Martin Tristani-Firouzi. hERG potassium channels and cardiac arrhythmia. Nature, 440(7083):463-469, 2006 Mar 23. 39

[72] Maurizio Recanatini, Elisabetta Poluzzi, Matteo Masetti, Andrea Cavalli, and Fabrizio De Ponti. QT prolongation through hERG $\mathbf{K}(+)$ channel blockade: current knowledge and strategies for the early prediction during drug development. Med Res Rev, 25(2):133-166, 2005 Mar. 3940

[73] Bernard Fermini and Anthony A Fossa. The impact of drug-induced QT interval prolongation on drug discovery and development. Nat Rev Drug Discov, 2(6):439-447, 2003 Jun. 39

[74] J S Mitcheson, J Chen, M Lin, C Culberson, and M C SAnguinetti. A structural basis for drug-induced long QT syndrome. Proc Natl Acad Sci USA, 97(22):12329-12333, 2000 Oct 24. 40

[75] Michael C Sanguinetti and John S Mitcheson. Predicting drug-hERG channel interactions that cause acquired long QT syndrome. Trends Pharmacol Sci, 26(3):119-124, 2005 Mar. 40

[76] H Suessbrich, S WALdegger, F LANG, AND A E Busch. Blockade of HERG channels expressed in Xenopus oocytes by the histamine receptor antagonists terfenadine and astemizole. FEBS Lett, 385(1-2):77-80, 1996 Apr 29. 40

[77] M A Goldberg, S P Dunning, and H F Bunn. Regulation of the erythropoietin gene: evidence that the oxygen sensor is a heme protein. Science, 242(4884):1412-1415, 1988 Dec 9. 43
[78] C G Viloria, F Barros, T Giraldez, D Gomez-Varela, and P DE LA PENA. Differential effects of amino-terminal distal and proximal domains in the regulation of human erg $\mathrm{K}(+)$ channel gating. Biophys $J$, 79(1):231-246, 2000 Jul. 44

[79] D WRAY. The roles of intracellular regions in the activation of voltage-dependent potassium channels. Eur Biophys J, 33(3):194-200, 2004 May. 44

[80] A C Epstein, J M Gleadle, L A McNeill, $\mathrm{K}$ S Hewitson, J O'Rourke, D R Mole, M Mukherji, E Metzen, M I Wilson, A Dhanda, Y M Tian, N Masson, D L Hamilton, P JaAkKola, R Barstead, J Hodgkin, P H Maxwell, C W Pugh, C J Schofield, and P J Ratcliffe. C. elegans EGL-9 and mammalian homologs define a family of dioxygenases that regulate HIF by prolyl hydroxylation. Cell, 107(1):43-54, Oct 2001. 45

[81] D Weinshenker, A Wei, L Salkoff, and J H Thomas. Block of an ether-a-go-go-like $\mathrm{K}(+)$ channel by imipramine rescues egl-2 excitation defects in Caenorhabditis elegans. J Neurosci, 19(22):98319840, 1999 Nov 15. 45

[82] O Staub, I Gautschi, $\mathrm{T}$ Ishikawa, $\mathrm{K}$ Breitschopf, A Ciechanover, L Schild, and D Rotin. Regulation of stability and function of the epithelial $\mathrm{Na}+$ channel $(\mathrm{ENaC})$ by ubiquitination. EMBO J, 16(21):6325-36, Nov 1997. 46

[83] Xiu Xia Sun, S Lynn Bostrom, and Leslie C Griffith. Alternative splicing of the eag potassium channel gene in Drosophila generates a novel signal transduction scaffolding protein. Mol Cell Neurosci, 40(3):338-43, Mar 2009. 46

[84] Jacques Pouyssegur, Frederic Dayan, and Nathalie M MAZure. Hypoxia signalling in cancer and approaches to enforce tumour regression. Nature, 441(7092):437-443, 2006 May 25. 47

[85] A Masi, A Becchetti, R Restano-Cassulini, S Polvani, G Hofmann, A M Buccoliero, M Paglierani, B Pollo, G L Taddei, P Gallina, N Di Lorenzo, S Franceschetti, E WANKE, AND A ARCANGELI. hERG1 channels are overexpressed in glioblastoma multiforme and modulate VEGF secretion in glioblastoma cell lines. Br J Cancer, 93(7):781-792, 2005 Oct 3. 47

[86] Jodi K Maranchie, James R Vasselli, Joseph Riss, Juan S Bonifacino, W Marston Linehan, and Richard D KlausNER. The contribution of VHL substrate binding and HIF1-alpha to the phenotype of VHL loss in renal cell carcinoma. Cancer Cell, 1(3):247-255, 2002 Apr. 48

[87] Xiaofeng Zheng, Sarah Linke, José M Dias, Xiaowei Zheng, Katarina Gradin, Tristan P Waluis, Brett $R$ Hamilton, Maria Gustafsson, Jorge L Ruas, Sarah Wilkins, Rebecca L Bilton, Kerstin Brismar, Murray L Whitelaw, Teresa Pereira, Jeffrey J Gorman, Johan Ericson, Daniel J Peet, Urban Lendahl, and Lorenz PoEllinger. Interaction with factor inhibiting HIF-1 defines an additional mode of crosscoupling between the Notch and hypoxia signaling pathways. Proc Natl Acad Sci U S A, 105(9):336873, Mar 2008. 48 
[88] Karim Mekhail, Lakshman Gunaratnam, Marie-Eve BonICALZI, AND Stephen LeE. HIF activation by pHdependent nucleolar sequestration of VHL. Nat Cell Biol, 6(7):642-647, 2004 Jul. 48

[89] Chung-Jiunan Jeng, Chi-Chen Chang, and Chin-Yung Tang. Differential localization of rat Eag1 and Eag2 $\mathrm{K}+$ channels in hippocampal neurons. Neuroreport, 16(3):229-233, 2005 Feb 28. 4849

[90] Guey-Mei Jow and Chung-Jiuan Jeng. Differential localization of rat Eag1 and Eag2 potassium channels in the retina. Neurosci Lett, 431(1):12-16, 2008 Jan 24. 4849

[91] JefF C Hoenner and Kartik Prabhakaran. Induced differentiation affords neuroblastoma cells protection from hypoxic injury. $J$ Pediatr Surg, 38(7):1069-1074, 2003 Jul. 49

[92] Tammie Bishop, Denis Gallagher, Alberto Pascual, Craig a lygate, Joseph P de Bono, Lynn G Nicholls, Patricia Ortega-Saenz, Henrik Oster, Bhathiya WiJeyekoon, Andrew I Sutherland, Alexandra Grosfeld, Julian Aragones, Martin Schneider, Katie van Geyte, Dania Teixeira, Antonio Diez-Juan, Jose Lopez-Barneo, Keith M Channon, Patrick H Maxwell, Christopher W Pugh, Alun M Davies, Peter Carmeliet, and Peter J RatCLIFFE. Abnormal sympathoadrenal development and systemic hypotension in PHD3-/- mice. Mo Cell Biol, 28(10):3386-400, May 2008. 49

[93] Klaus Ballany. Protective role of neuronal KATP channels in brain hypoxia. $J$ Exp Biol, 207(Pt 18):3201-3212, 2004 Aug. 49

[94] Nobuyoshi Tajima, Kristina Schonherr, Susanna Niedling, Martin KaAtz, Hiroshi Kanno, Roland Schonherr, and Stefan H Heinemann. Ca2+-activated $\mathbf{K}+$ channels in human melanoma cells are up-regulated by hypoxia involving hypoxia-inducible factor-1alpha and the von Hippel-Lindau protein. J Physiol, 571(Pt 2):349-359, 2006 Mar 1. 49

[95] PD HRdina. Basic neurochemistry: Molecular, cellular and medical aspects - Siegel,GJ. Journal of Psychiatry \&3 Neuroscience, 21(5):352-353, November 1996. 49

[96] Susan J Vannucdi and Henrik Hagberg. Hypoxiaischemia in the immature brain. $J$ Exp Biol, $207(\mathrm{Pt}$ 18):3149-3154, 2004 Aug. 49

[97] C Grimm, D m Hermann, A Bogdanova, S Hotop, U Kilic, A Wenzel, E Kilic, and M Gassmann. Neuroprotection by hypoxic preconditioning: HIF-1 and erythropoietin protect from retinal degeneration. Semin Cell Dev Biol, 16(4-5):531-538, 2005 Aug-Oct. 49

98] David A Greenberg And Kunlin Jin. From angiogenesis to neuropathology. Nature, 438(7070):954-959, 2005 Dec 15. 49

[99] Erik Storkebaum, Diether Lambrechts, and Peter CARMELIET. VEGF: once regarded as a specific angiogenic factor, now implicated in neuroprotection. Bioessays, 26(9):943-954, 2004 Sep. 49

[100] Gui-Rong Li, Haiying Sun, Xiuling Deng, and Chu-Pak LAU. Characterization of ionic currents in human mesenchymal stem cells from bone marrow. Stem Cells, 23(3):371-382, 2005 Mar. 50

[101] Victoria A L Tomlinson, Helen J Newbery, Naomi R Wray, Juliette Jackson, Alexey Larionov, William R Miller, J Michael Dixon, and Catherine M AbBott. Translation elongation factor eEF1A2 is a potential oncoprotein that is overexpressed in twothirds of breast tumours. BMC Cancer, 5:113, 2005. 50 .

[102] O P Hamill, A Marty, E Neher, B Sakmann, and F J SIGWORTH. Improved patch-clamp techniques for high-resolution current recording from cells and cell-free membrane patches. Pflugers Arch, 391(2):85-100, Aug 1981. 52

[103] Rafael E García-Ferreiro, Daniel Kerschensteiner, Felix Major, Francisco Monje, Walter Stühmer, and Luis A PARDO. Mechanism of block of hEag1 K+ channels by imipramine and astemizole. J Gen Physiol, 124(4):301-17, Oct 2004. 52

[] Rafael E Garcia-Ferreiro, Daniel Kerschensteiner, Felix Major, Francisco Monje, Walter Stuhmer, and Luis A PARDO. Mechanism of block of hEag1 K+ channels by imipramine and astemizole. J Gen Physiol, 124(4):301-317, 2004 Oct.

[104] Young Ho Koh, Christine A F von Arnim, Bradley T Hyman, Rudolph E Tanzi, and Giuseppina Tesco. BACE is degraded via the lysosomal pathway. J Biol Chem, 280(37):32499-504, Sep 2005. 53

[105] Joanna Napp, Francisco Monje, Walter Stuhmer, and LUIS A PARDo. Glycosylation of Eag1 (Kv10.1) potassium channels: intracellular trafficking and functional consequences. $J$ Biol Chem, 280(33):29506-29512, 2005 Aug 19. 54 


\section{Declaration}

I herewith declare that I have produced this paper without the prohibited assistance of third parties and without making use of aids other than those specified; notions taken over directly or indirectly from other sources have been identified as such. This paper has not previously been presented in identical or similar form to any other German or foreign examination board. The thesis work was conducted from 2004 to 2009 under the supervision of Dr. Luis Pardo at the Max Planck Institute for Experimental Medicine, Göttingen, Germany.

Göttingen, Germany, 